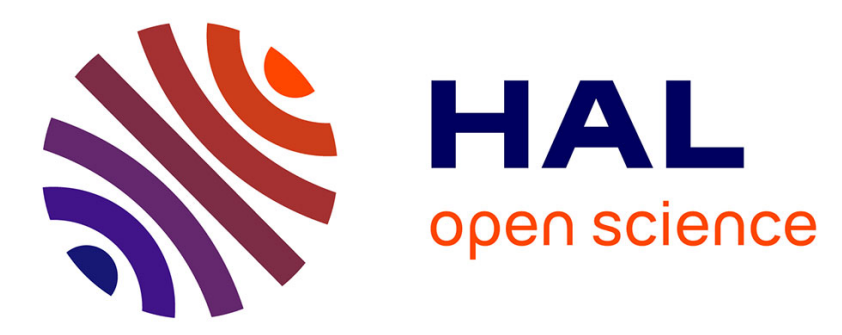

\title{
Lanthanide-based hexa-nuclear complexes and their use as molecular precursors.
}

\author{
Guillaume Calvez, François Le Natur, Carole Daiguebonne, Kevin Bernot, \\ Yan Suffren, Olivier Guillou
}

\section{- To cite this version:}

Guillaume Calvez, François Le Natur, Carole Daiguebonne, Kevin Bernot, Yan Suffren, et al.. Lanthanide-based hexa-nuclear complexes and their use as molecular precursors.. Coordination Chemistry Reviews, 2017, 340, pp.134-153. 10.1016/j.ccr.2016.12.004 . hal-01419228

\section{HAL Id: hal-01419228 \\ https://hal.science/hal-01419228}

Submitted on 28 Sep 2017

HAL is a multi-disciplinary open access archive for the deposit and dissemination of scientific research documents, whether they are published or not. The documents may come from teaching and research institutions in France or abroad, or from public or private research centers.
L'archive ouverte pluridisciplinaire HAL, est destinée au dépôt et à la diffusion de documents scientifiques de niveau recherche, publiés ou non, émanant des établissements d'enseignement et de recherche français ou étrangers, des laboratoires publics ou privés. 


\section{Lanthanide-based hexa-nuclear complexes and their use as}

\section{molecular precursors.}

Guillaume Calvez ${ }^{\mathrm{a}}$, François Le Natur ${ }^{\mathrm{a}, \mathrm{b}}$, Carole Daiguebonne ${ }^{\mathrm{a}}$, Kevin Bernot ${ }^{\mathrm{a}}$, Yan Suffren ${ }^{\mathrm{a}}$ and Olivier Guillou ${ }^{\mathrm{a}, *}$

a INSA Rennes, UMR 6226 "Institut des Sciences Chimiques de Rennes", 20 Avenue des buttes de Coësmes, F-35708 Rennes.

${ }^{\mathrm{b}}$ Present address: Olnica SAS, 40 rue du Bignon, F-35135 Chantepie.

* To whom correspondence should be addressed. 


\begin{abstract}
The use of lanthanide-based poly-nuclear complexes as molecular precursor for the design of extended molecular frameworks is still an innovative synthesis strategy. Oxohydroxo poly-nuclear complexes are generally obtained by controlling $\mathrm{pH}$ conditions during reaction process. After a short description of the lanthanide hydrolysis phenomenon and a non-exhaustive inventory of existing complexes with increasing nuclearity, the present review focuses on lanthanide-based hexa-nuclear oxo-hydroxo complexes. Their syntheses and crystal structures are described and their interest as building blocks for the design of new coordination compounds with unprecedented physical properties is highlighted.
\end{abstract}

\title{
Keywords
}

Hexa-nuclear complexes; Coordination compounds; Molecular precursor; Crystal structures; Photophysical properties 


\section{Contents}

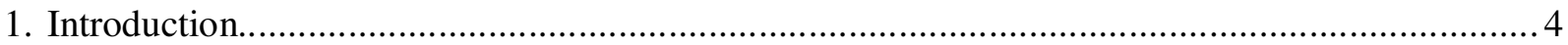

2. Hydrolysis of the lanthanide ions .................................................................................. 7

3. Synthesis of the poly-nuclear oxo-hydroxo lanthanide-based complexes .............................. 9

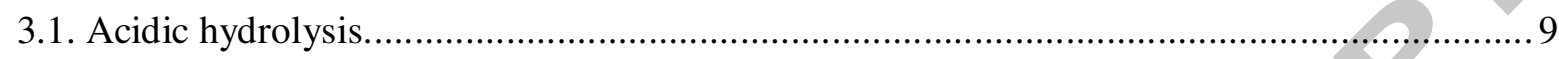

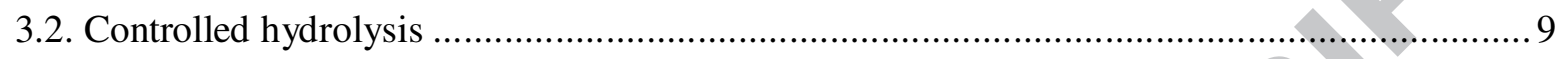

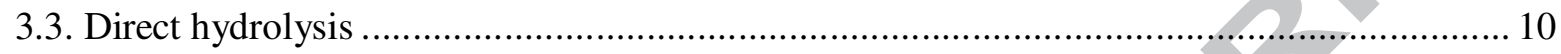

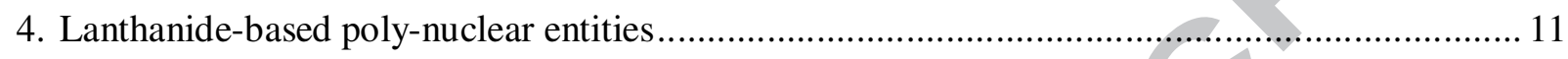

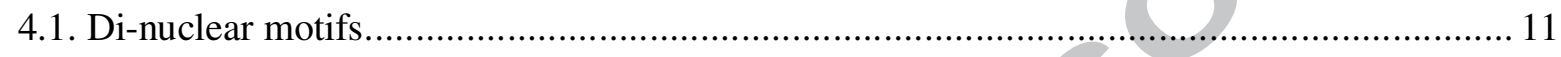

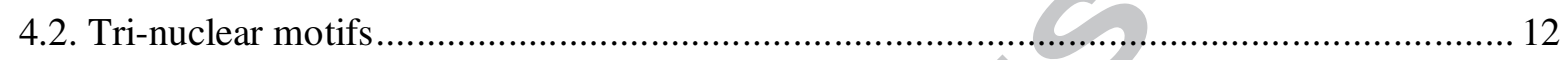

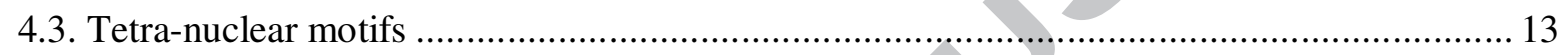

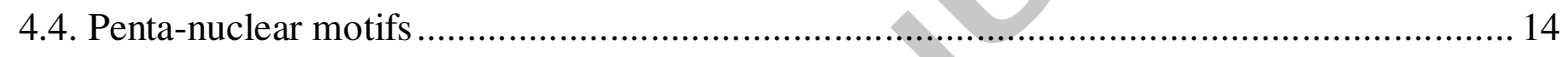

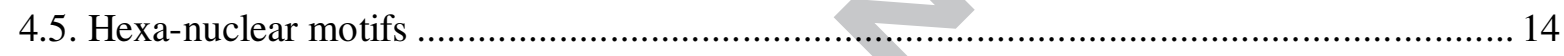

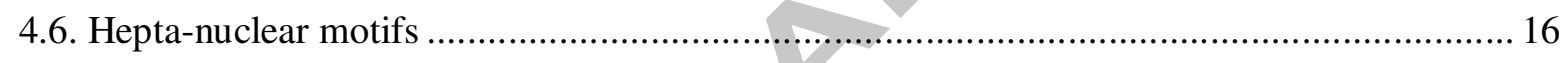

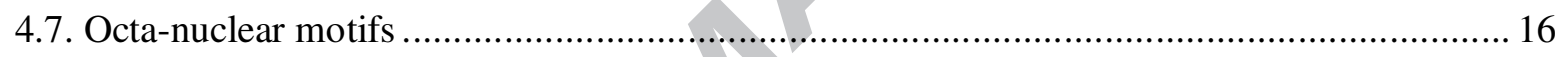

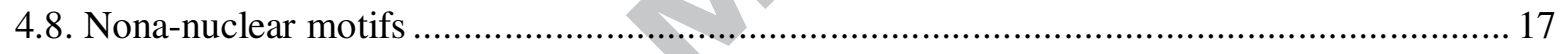

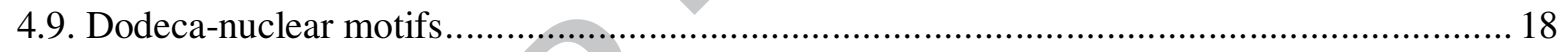

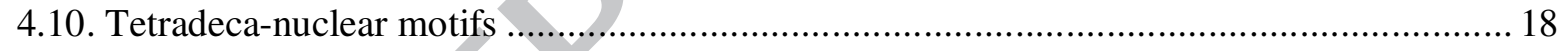

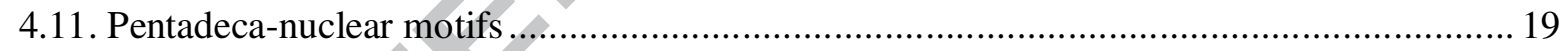

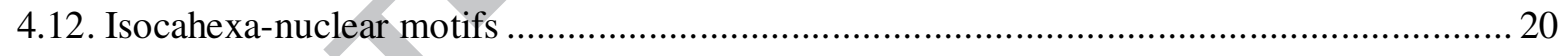

4.13. Poly-nuclear motifs with higher nuclearity........................................................ 21

5. Synthesis and stability of the octahedral hexa-nuclear entities .......................................... 23

6. From hexa-nuclear precursors to coordination polymers...................................................... 37

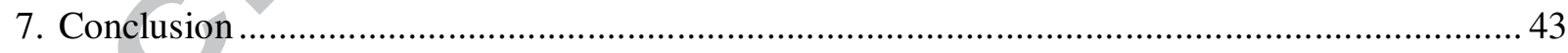

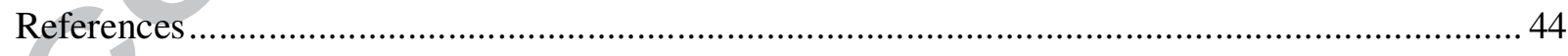




\section{Introduction}

For almost two decades there is an increasing interest for the design of new lanthanide-based complexes or coordination polymers. Indeed lanthanide-based coordination compounds can find their application in various fields as diverse as gas separation [1], immunoassays [2, 3], lighting or fight against counterfeiting [4] and telecommunication [5] for instance. Optimization of the physical properties implies a control of the crystal structure of the compounds [6-10]. In coordination chemistry this can be achieved either by acting on the ligand or on the metallic center. Most often, the first strategy is retained [11] and numerous beautiful coordination compounds with excellent physical properties have been obtained thanks to tailored ligands $[12,13]$. One of the limitation of this approach lies in the synthesis of the ligand itself that can be low yield and/or high cost which constitute drawbacks as far as potential applications are targeted. A second limitation is related to the chemical properties of the rare earth ions: because of the shielded character of their valence orbitals, they present almost no structuring effect [14] and the stability of the molecular frameworks is essentially insured by weak inter-molecular interactions such as hydrogen bonds or $\pi$-stacking. This most often induces a great structural variety of the coordination compounds that are accessible from given lanthanide ion and ligand $[15,16]$. Therefore, resorting to the second strategy, which consists in the design of molecular precursors usable as structuring metallic nodes, sounds appealing. In this synthetic approach, the metallic node is no longer a single ion but a poly-nuclear complex. Substitution of mono-topic terminal ligands by poly-topic ones leads to extended molecular frameworks whose topology is influenced by the geometry of the poly-nuclear complex (See Scheme 1). This approach implies that the structure of the poly-metallic core is retained after the substitution. Therefore the complex precursor must present sizeable solubility in solvents and quite good thermal and 
chemical stabilities. Because of these quite demanding requirements, the materials that have been obtained according to this strategy are rather scarce (Table 1).

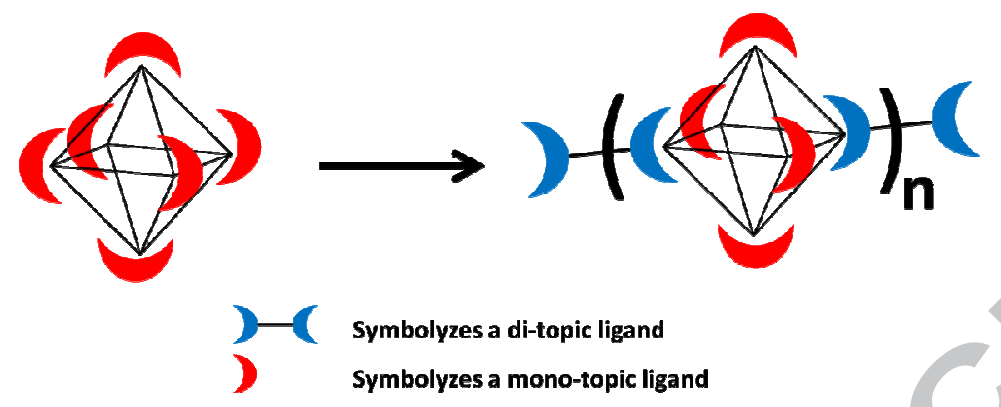

Scheme 1. Schematic representation of the substitution of mono-topic ligands by di-topic ones.

\section{Table 1}

Coordination polymers obtained from a poly-metallic molecular precursor.

Lrecursor




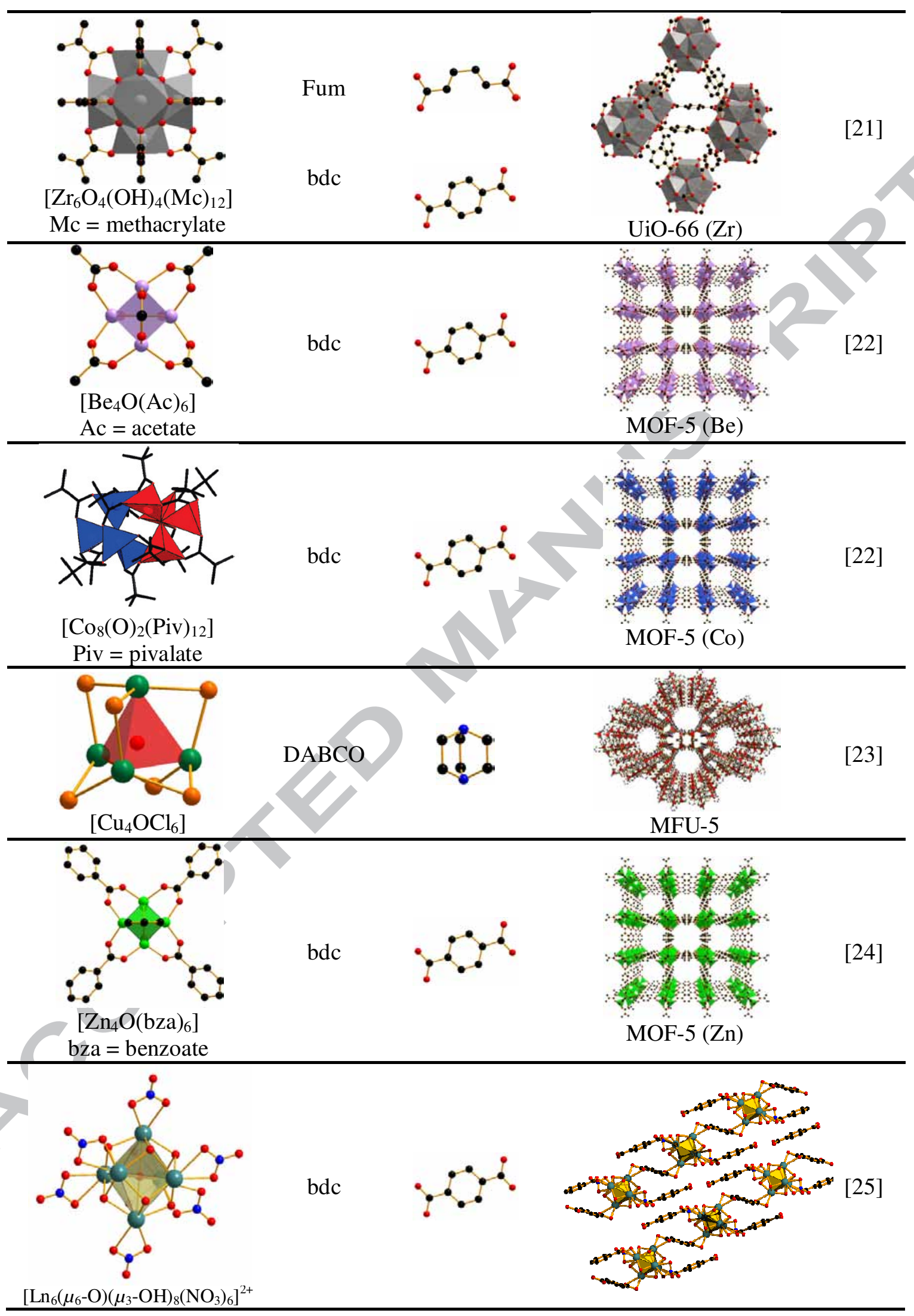


Fum = butene-dicarboxylate, bdc $=$ benzene-1,4-dicarboxylate, ndc $=2,6$ naphtalenedicarboxylate, bpdc $=4,4$ '-biphenyldicarboxylate, $\mathrm{NH}_{2} \mathrm{bdc}=2$-aminoterephtalate, $\mathrm{DABCO}=1,4$-diazabicyclo[2.2.2.]octane.

It can be noticed from Table 1 that, to date, there is only one example of lanthanidebased coordination polymer that have been obtained from a poly-nuclear complex. Compounds that constitute the scope of this review present multi-dentate $\mathrm{O}^{2-}$ or $\mathrm{OH}$ groups and even if most of them have a protecting shell made of organic ligands their metallic core remains essentially inorganic. Consequently, despite fascinating crystal structures [26], compounds obtained by lanthanide alkoxyde-based chemistry do not enter in the scope of this review. In this review, we focus our attention on hexa-nuclear oxo-hydroxo complexes. Their syntheses, their crystal structures and their chemical stability will be described. The interest of using them as molecular precursors is highlighted as well as the last achievements in this field.

\section{Hydrolysis of the lanthanide ions.}

In acidic aqueous solutions, it is commonly admitted that lanthanide ions exist as aquo-ions with general chemical formula $\left[\mathrm{Ln}\left(\mathrm{H}_{2} \mathrm{O}\right)_{n}\right]^{3+}$ where $n=9$ for $\mathrm{Ln}=\mathrm{La}-\mathrm{Nd}$ except $\mathrm{Pm}$ and $n=8$ for $\mathrm{Ln}=$ Dy-Lu plus Y. Intermediate situation is observed for Ln comprised between $\mathrm{Sm}$ and $\mathrm{Tb}$ [27]. As the $\mathrm{pH}$ increases, mono- or poly-nuclear hydroxyl-salts are

formed, with general core formula $\left[\mathrm{Ln}(\mathrm{OH})_{q} \mathrm{~L}_{p}\right]^{(3-q-p)+}$ where $\mathrm{L}$ symbolizes the counter anion of the starting lanthanide salt [28-32]. Some of these species have been isolated in the solid state and structurally characterized [33]. If the hydrolysis goes on, lanthanide tri-hydroxide is obtained. Its crystal structure can be described as a 3D network in which nona-coordinated lanthanide ions are linked by $\mu_{3}-\mathrm{OH}$ groups [34] (See Fig. 1 for an example). 

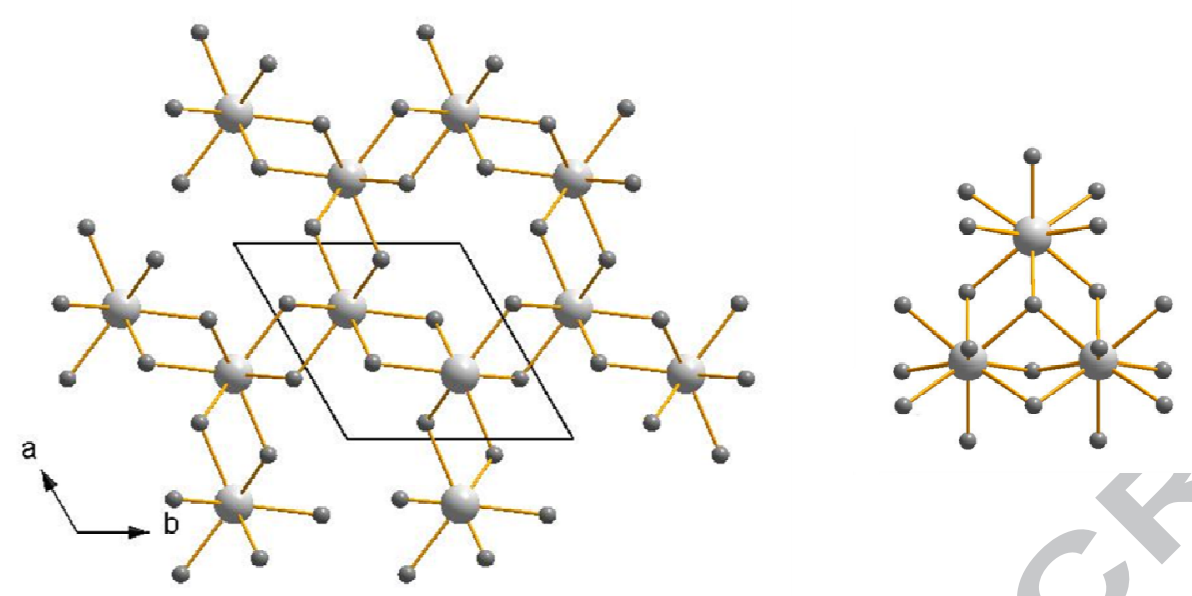

Fig. 1. Left: Projection view along the $c$-axis of $\mathrm{Nd}(\mathrm{OH})_{3}$. Right: Projection view of an $\mu_{3}-\mathrm{OH}$ group. Redrawn from reference [34]. Light and dark grey balls are respectively for lanthanide, and oxygen atoms.

Lanthanide tri-hydroxides present solubility that decreases with the ionic radius of the involved lanthanide ion. Solubility products $\left(\mathrm{K}_{\mathrm{S}}=\left[\mathrm{Ln}^{3+}\right] \times\left[\mathrm{OH}^{-}\right]^{3}\right)$ measured at $25{ }^{\circ} \mathrm{C}[35]$ are listed in Table 2. Therefore, lanthanide tri-hydroxides precipitate at slightly acidic $\mathrm{pH}$ (typically for $5.5<\mathrm{pH}<7.5$ ) [36] and the poly-nuclear complexes are obtained at lower $\mathrm{pH}$ (typically for $4<\mathrm{pH}<7$ ) [37].

Table 2

Solubility products of $\mathrm{Ln}(\mathrm{OH})_{3}$ versus $\mathrm{Ln}^{3+}$ ions at $25^{\circ} \mathrm{C}$.

\begin{tabular}{lllllllllllll}
\hline $\mathrm{Ln}$ & $\mathrm{La}$ & $\mathrm{Ce}$ & $\mathrm{Pr}$ & $\mathrm{Nd}$ & $\mathrm{Sm}$ & $\mathrm{Eu}$ & $\mathrm{Gd}$ & $\mathrm{Dy}$ & $\mathrm{Ho}$ & $\mathrm{Er}$ & $\mathrm{Yb}$ & $\mathrm{Lu}$ \\
$\log \left(\mathrm{K}_{\mathrm{s}}\right)$ & 20.3 & 20.8 & 20.5 & 18.9 & 16.6 & 16.4 & 16.3 & 16.4 & 16.1 & 17.1 & 17.0 & 15.9 \\
\hline
\end{tabular}

Poly-nuclear oxo-hydroxo complexes are obtained when the condensation is stopped by the presence of terminal chelating groups or counter anions, in the coordination sphere of the lanthanide ions. 


\section{Synthesis of the poly-nuclear oxo-hydroxo lanthanide-based complexes.}

\subsection{Acidic hydrolysis}

It is possible to obtain poly-nuclear oxo-hydroxo lanthanide complexes in acid media by acidolysis [38, 39]. Typically, an aqueous suspension of a lanthanide precursor (oxide or salt) and of a ligand at acidic $\mathrm{pH}\left(\right.$ typically $\mathrm{pH}<3$ ) is kept in a Teflon ${ }^{\mathrm{TM}}$-lined stainless steel vessel at about $150{ }^{\circ} \mathrm{C}$ (hydrothermal synthesis). During the process, precursors solubilize and hydrolyze. This method has provided some coordination compounds with lanthanide-based poly-nuclear oxo-hydroxo cores [40-42] but none of these compounds has been used as a molecular precursor.

\subsection{Controlled hydrolysis}

This method consists in increasing the $\mathrm{pH}$ of a solution that initially contains a dissolved lanthanide ion and a ligand. Nature of the ligand, of the base and of the solvent, the temperature and the relative concentrations of the different species highly influence hydrolysis. In the 2000's, Zheng et al. have developed this chemistry and have drawn its main trends [43-45]. Thanks to a synthetic strategy based on the use of amino acids as ligand, they have obtained numerous fascinating coordination compounds with lanthanide-based polynuclear cores ranging from tetra-nuclear cores to hexaconta-nuclear cores [37, 43, 46-53]. $\beta$-diketonates [54-56], alkoxides [57-59], phenoxides [60] or nitrophenolates [61, 62] have also widely been used as ligand. Recently, Eddaoudi et al. have obtained a series of compounds that illustrate the structuring character of lanthanide-based poly-nuclear cores [6367]. These coordination polymers, obtained in hydrothermal conditions from lanthanide nitrate and fluoro-carboxylic acids present poly-nuclear metallic nodes that are linked to each other by their vertices (Fig. 2). Some of them present promising gas storage properties [67]. 

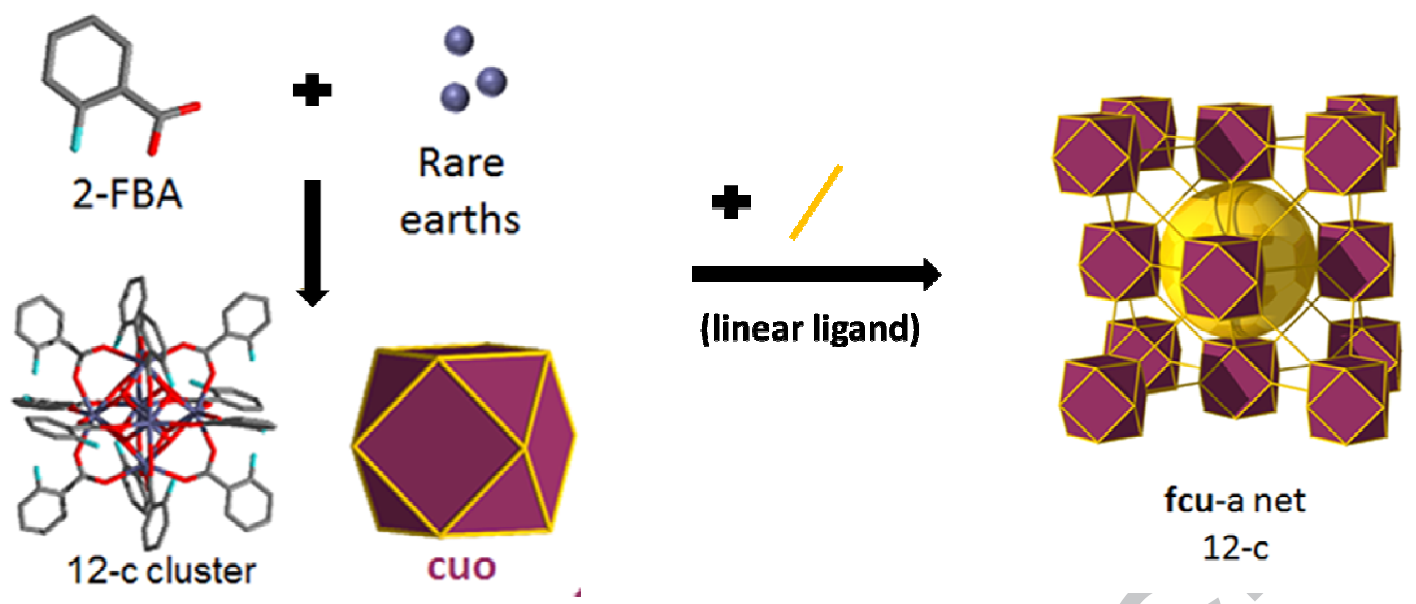

Fig. 2. Illustration of the structuring effect of lanthanide-based poly-nuclear nodes. Redrawn from reference [64].

Despite the fascinating crystal structures presented by the coordination compounds provided by this synthetic pathway, no poly-nuclear complex usable as a molecular building block has been obtained. Indeed this strategy presents a significant drawback as far as molecular precursors are targeted. It is a one pot synthetic strategy that leads to species that present external and/or bridging ligands which prevent the poly-nuclear cores from further condensation but cannot be removed or substituted without destroying them.

\subsection{Direct hydrolysis}

Direct hydrolysis of the lanthanide ions can also lead to lanthanide-based oxo-hydroxo coordination compounds. Historically this approach has led to the first lanthanide-based polynuclear oxo-hydroxo isolated complexes [68-75]. This synthetic strategy consists in increasing the $\mathrm{pH}$ of a concentrated solution of a lanthanide salt by a controlled addition of a basic solution. This addition must be done with great care [76] because it must neither induce a significant dilution of the lanthanide solution nor provoke precipitation of insoluble polymeric species such as $\mathrm{Ln}(\mathrm{OH})_{2}\left(\mathrm{NO}_{3}\right)$ [73, 74], $\mathrm{LnONO}_{3}$ [77] or $\mathrm{Ln}(\mathrm{OH})_{3}$ [34]. Whatever 
the used starting lanthanide salt (perchlorate $[44,47,78,79]$ or nitrate $[69,75,76,80-82]$ ), this synthetic process leads to hexa-nuclear oxo-hydroxo complexes. When the starting lanthanide salt is a nitrate, nitrate ions coordinate the lanthanide ions and act as protecting ligands for the hexa-nuclear complex. These hexa-nuclear complexes constitute the core of this review because they can be isolated and used as molecular precursors for further chemistry.

\section{Lanthanide-based poly-nuclear entities}

Before focusing our attention on hexa-nuclear complexes, it is interesting to have a brief survey of the other lanthanide-based poly-nuclear cores encountered in the literature. We have focused our attention on edifices where oxo or hydroxo groups play a fundamental role. Other lanthanide-based poly-nuclear complexes exist especially in the dynamic field of molecular magnetism [83].

\subsection{Di-nuclear motifs}

These motifs (" $\left.\mathrm{Ln}_{2}\left(\mu_{2}-\mathrm{OH}\right)_{2} "\right)$ are very common in coordination compounds. They are observed in dimeric isolated molecules or in coordination polymers in which they act as metallic nodes. Lanthanide ions are bridged by two [84], three [85] or four [86] oxygen atoms from hydroxo [87], aquo [88], carboxylates [89] or diketonates [90-92] groups for instance (Fig. 3). Their hydrolyze rate, hereafter symbolized by "h" and defined as the number of $\mathrm{OH}^{-}$ groups per lanthanide ion [76], is equal to 1 . The formal charge of the di-nuclear core is equal to +4 . 


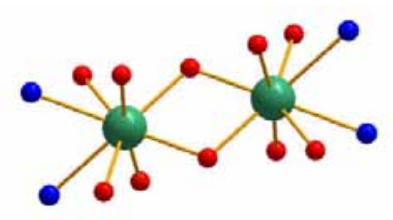

Fig. 3. Di-nuclear motif " $\mathrm{Ln}_{2}\left(\mu_{2}-\mathrm{OH}\right)_{2} "\left(3.8<\mathrm{d}_{\mathrm{Ln}-\mathrm{Ln}}(\AA)<4.05\right)$. Redrawn from reference [84]. Blue, red and green balls stand for nitrogen, oxygen and lanthanide atoms respectively.

\subsection{Tri-nuclear motifs}

In this motif (" $\left.\operatorname{Ln}_{3}\left(\mu_{3}-\mathrm{OH}\right)_{2} "\right)$, lanthanide ions constitute a triangle capped by one or two $\mu_{3}$-hydroxo groups [93-96] (Fig. 4). The formal charge of the tri-nuclear core is +7 . Alternatively one hydroxo group can be replaced by a chloride [97, 98] or a sulfate [97] ion (in that case, the formal charge of the tri-nuclear core is +6). In all cases, these motifs are protected by organic ligands. Recently, a Dy-containing 2D coordination polymer exhibiting slow relaxation of the magnetization has been reported. This structure has been described on the basis of " $\operatorname{Ln}_{3}\left(\mu_{3}-\mathrm{OH}\right)_{2}$ " motifs that share sides to form infinite molecular ribbons [99, $100]$.

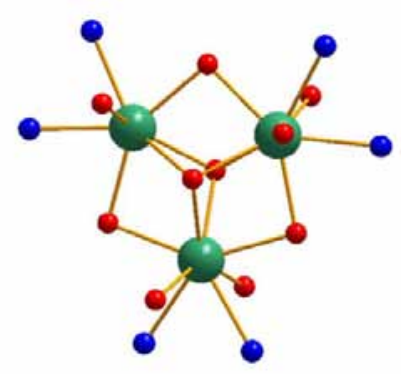

Fig. 4. Tri-nuclear motif " $\operatorname{Ln}_{3}\left(\mu_{3}-\mathrm{OH}\right)_{2}$ " $\left(\mathrm{h}=0.67\right.$ and $\left.3.5<\mathrm{d}_{\mathrm{Ln}-\mathrm{Ln}}(\AA)<3.6\right)$. Redrawn from reference [95]. Blue, red and green balls stand for nitrogen, oxygen and lanthanide atoms respectively. 


\subsection{Tetra-nuclear motifs}

There are two tetra-nuclear motifs: the "cubane" one $\left(" \mathrm{Ln}_{4}\left(\mu_{3}-\mathrm{OH}\right)_{4} "\right)$ and the "lozenge" one ("Ln $\left.4\left(\mu_{3}-\mathrm{OH}\right)_{2} "\right)($ Fig. 5).

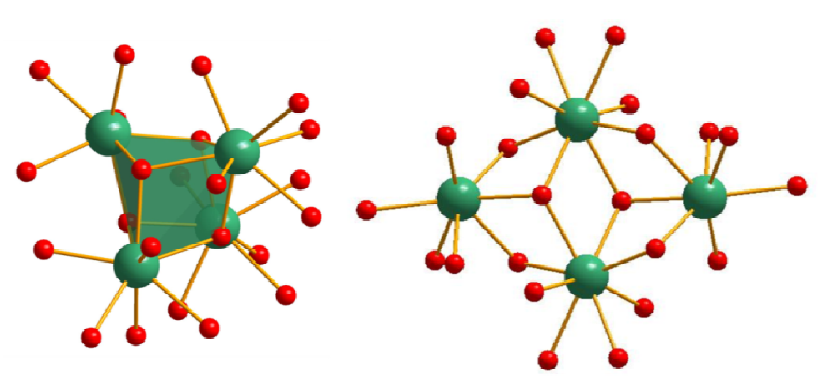

Fig. 5. Left: Cubane-like tetra-nuclear motif $\left(h=1\right.$ and $\left.3.75<d_{\operatorname{Ln}-\operatorname{Ln}}(\AA)<3.9\right)$. Redrawn from reference [35]. Right: lozenge-like tetra-nuclear motif $\left(h=0.5 .3 .6<d_{\operatorname{Ln}-\operatorname{Ln}}(\AA)<4.3\right)$. Redrawn from reference [101]. Red and green balls stand for oxygen and lanthanide atoms respectively.

The cubane-like tetra-nuclear entity is one of the most commonly encountered polynuclear motifs. It has been observed in isolated molecules [102-104] as well as in coordination polymers $[37,105]$ in association with various ligands such as amino-acids $[35$, 52, 106, 107], EDTA [46, 48], carboxylic acids [51, 101-103, 105] or $\beta$-diketones [108, 109] for example. Four lanthanide ions are located on four of the vertices of a distorted cube. Oxygen atoms of $\mu_{3}-\mathrm{OH}$ groups occupy the others vertices. This motif has been often evoked for describing poly-nuclear cores of higher nuclearity. The formal charge of this core is +8 .

The lozenge tetra-nuclear is less common. It has been first obtained by thermal decomposition of an yttrium acetylacetonate [110]. Since that time, this motif has been encountered several times [101, 111-114]. Lanthanide ions constitute a lozenge and are linked to each other by $\mu_{3}-\mathrm{OH}$ groups. The formal charge of the core is +10 . 


\subsection{Penta-nuclear motifs}

Penta-nuclear motifs ("Ln $\left.5\left(\mu_{4}-\mathrm{OH}\right)\left(\mu_{3}-\mathrm{OH}\right)_{4} "\right)$ have been widely studied [115-126]. In this motif, lanthanide ions form a square-based pyramid. Each face of the pyramid is capped by a $\mu_{3}-\mathrm{OH}$ group and the square base is capped by a $\mu_{4}-\mathrm{OH}$ group (Fig. 6). In all crystal structures, this motif is decorated by organic ligands that prevent the penta-nuclear core destruction. However, it is noticeable that some compounds have been obtained in two steps although no penta-nuclear-based complex has been used as a previously isolated reactant. The formal charge of the core is +10 .

Another penta-nuclear motif (" $\left.\operatorname{Ln}_{5}\left(\mu_{3}-\mathrm{OH}\right)_{6} "\right)$ in which lanthanide ions form a trigonal bi-pyramid has also been reported once [127] (Fig. 6.). The formal charge of this pentanuclear core is +9 .

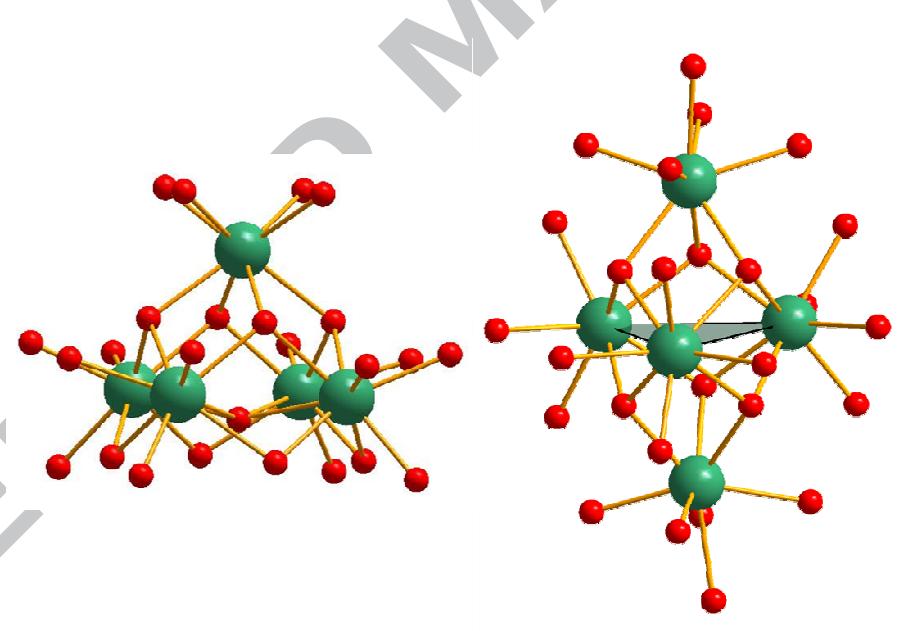

Fig. 6. Left: Square-based pyramidal penta-nuclear motif " $\operatorname{Ln}_{5}\left(\mu_{4}-\mathrm{OH}\right)\left(\mu_{3}-\mathrm{OH}\right)_{4} "(\mathrm{~h}=1$ and $\left.3.5<\mathrm{d}_{\text {Ln-Ln }}(\AA)<3.8\right)$. Redrawn from reference [115]. Right: Trigonal bi-pyramidal motif "Ln $5\left(\mu_{3}-\mathrm{OH}\right)_{6}$ " $\left(\mathrm{h}=1.2\right.$ and $\left.3.7<\mathrm{d}_{\text {Ln-Ln }}(\AA)<3.9\right)$. Redrawn from reference [127]. Red and green balls stand for oxygen and lanthanide atoms respectively.

4.5. Hexa-nuclear motifs 
Three different hexa-nuclear motifs have been described. One out of them can be described as the association of two triangular tri-nuclear motifs [128]. The two others present respectively a chair-like motif $\left(" \operatorname{Ln}_{6}\left(\mu_{3}-\mathrm{OH}\right)_{4}\right)$ and an octahedral motif $\left(" \operatorname{Ln}_{6}\left(\mu_{6}-\mathrm{O}\right)\left(\mu_{3^{-}}\right.\right.$ $\mathrm{OH})_{8} "$ ) (Fig. 7). To the best of our knowledge, the former motif has been isolated only once [129]. Lanthanide ions are arranged in a chair-like way. They are linked to each other by $\mu_{3}-$ $\mathrm{OH}$ groups. The formal charge of this hexa-nuclear core is +14 .
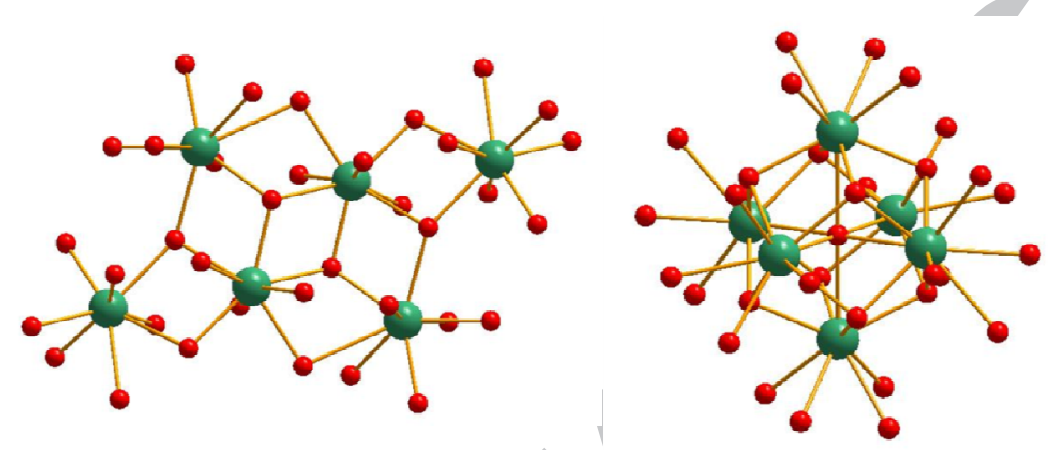

Fig. 7. Left: Chair-like hexa-nuclear motif " $\mathrm{Ln}_{6}\left(\mu_{3}-\mathrm{OH}\right)_{4} "\left(\mathrm{~h}=0.67\right.$ and $3.7<\mathrm{d}_{\mathrm{Ln}-\mathrm{Ln}}(\AA)<$ 3.8). Redrawn from reference [129]. Right: Octahedral hexa-nuclear motif "Ln $6\left(\mu_{6}-\mathrm{O}\right)\left(\mu_{3}-\mathrm{OH}\right)_{8} "\left(\mathrm{~h}=1.67\right.$ and 3.4 $\left.<\mathrm{d}_{\mathrm{Ln}-\mathrm{Ln}}(\AA)<3.6\right)$. Redrawn from reference [68]. Red and green balls stand for oxygen and lanthanide atoms respectively.

The octahedral hexa-nuclear motif (" $\left.\mathrm{Ln}_{6}\left(\mu_{6}-\mathrm{O}\right)\left(\mu_{3}-\mathrm{OH}\right)_{8} "\right)$ has been first described in 1994 by Zdirad, Unfried and Giester [72]. Lanthanide ions occupy the vertices of a quasiperfect octahedron whose each face is capped by a $\mu_{3}-\mathrm{OH}$ group. A $\mu_{6}-\mathrm{O}$ is located at the center of the octahedron. This oxygen atom contributes to the stability of the hexa-nuclear motif. The formal charge of this oxo-hydroxo core is +8 . There is no organic ligand in the coordination sphere of the lanthanides ions. Only coordination water molecules and sometimes counter anions (nitrate or perchlorate) complete the coordination sphere. This hexa-nuclear motif has been observed in the solid state in complexes $[46,47,49,79,80,130$ $138]$ or in coordination polymers $[25,40,41,139-144]$ and in the liquid state as nano- 
aggregates [145]. To the best of our knowledge, hexa-nuclear complexes are the only polynuclear complexes that have been used as molecular precursors so far.

\subsection{Hepta-nuclear motifs}

Hepta-nuclear motifs (" $\mathrm{Ln}_{7}\left(\mu_{3}-\mathrm{OH}\right)_{8}$ ") have been observed in coordination polymers $[146,147]$. They can be described as the condensation of two cubane-like motifs that would share a vertex (See Fig. 8). The formal charge of the core is +13 . Another star-like heptanuclear motifs $\left(" \operatorname{Ln}_{7}\left(\mu_{3}-\mathrm{OH}\right)_{6}\right.$ ") has been encountered only once [148]. The formal charge of the core is +15 .

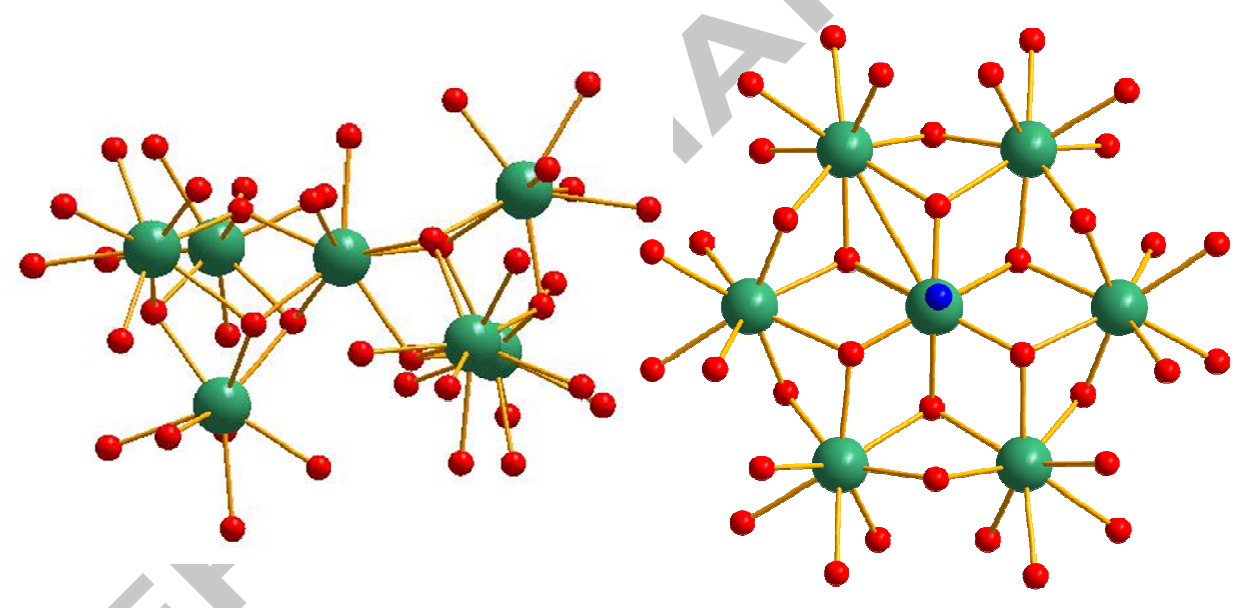

Fig. 8. Left: Hepta-nuclear motif " $\operatorname{Ln}_{7}\left(\mu_{3}-\mathrm{OH}\right)_{8} "\left(h=1.1\right.$ and $\left.3.6<\mathrm{d}_{\mathrm{Ln}-\mathrm{Ln}}(\AA)<3.8\right)$. Redrawn from reference [146]. Right: Star like heptanuclear motif " $\mathrm{Ln}_{7}\left(\mu_{3}-\mathrm{OH}\right)_{6}$ ". $(\mathrm{h}=0.85$ and $3.7<$ $\left.\mathrm{d}_{\text {Ln-Ln }}(\AA)<3.9\right)$. Redrawn from reference [148]. Blue, red and green balls stand for nitrogen, oxygen and lanthanide atoms respectively.

\subsection{Octa-nuclear motifs}

Octa-nuclear motifs $\left(" \operatorname{Ln}_{8}\left(\mu_{4}-\mathrm{O}\right)\left(\mu_{3}-\mathrm{OH}\right)_{12} "\right)$ have been observed only with $\beta$-diketonate tetramethyl-heptan-di-one as ligand [149-152]. They can be described as two 
cubane-like motifs linked to each other by a $\mu_{4}-\mathrm{O}$ atom (Fig. 9). The formal charge of the core is +10 .

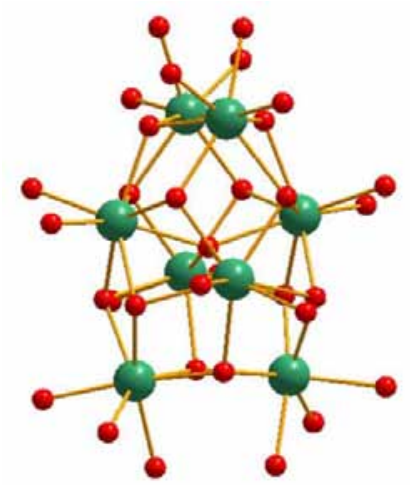

Fig. 9. Octa-nuclear motif " $\operatorname{Ln}_{8}\left(\mu_{4}-\mathrm{O}\right)\left(\mu_{3}-\mathrm{OH}\right)_{12} "\left(\mathrm{~h}=1.75\right.$ and $\left.3.4<\mathrm{d}_{\mathrm{Ln}-\operatorname{Ln}}(\AA)<3.8\right)$. Redrawn from reference [150]. Red and green balls stand for oxygen and lanthanide atoms respectively.

\subsection{Nona-nuclear motifs.}

Sandglass-like nona-nuclear motifs $\left(" \mathrm{Ln}_{9}\left(\mu_{4}-\mathrm{O}\right)\left(\mu_{4}-\mathrm{OH}\right)\left(\mu_{3}-\mathrm{OH}\right)_{8} "\right)$ have been observed in several coordination compounds [150, 152-156]. They can be described as two square-base pyramids that would share their summits (Fig. 10). The formal charge of the core is +16 .

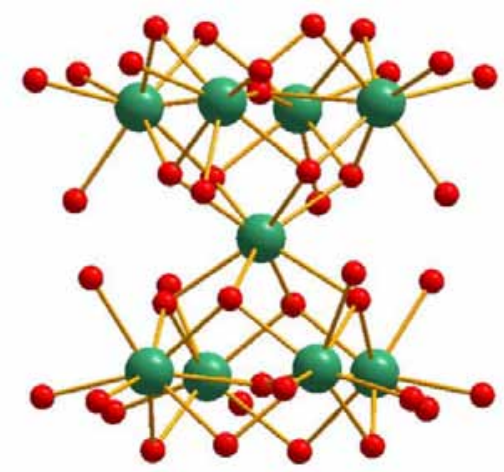

Fig. 10. Sandglass-like nona-nuclear motifs " $\mathrm{Ln}_{9}\left(\mu_{4}-\mathrm{O}\right)\left(\mu_{4}-\mathrm{OH}\right)\left(\mu_{3}-\mathrm{OH}\right)_{8} "(\mathrm{~h}=1.2$ and $3.6<$ $\left.\mathrm{d}_{\text {Ln-Ln }}(\AA)<3.7\right)$. Redrawn from reference [156]. Red and green balls stand for oxygen and lanthanide atoms respectively. 
It can be noticed that the first spectroscopic and structural study of hetero-poly-nuclear lanthanide-based compounds has been realized on one of these complexes [156] ("Ln ${ }_{9-x} \mathrm{Ln}_{x}^{\prime}\left(\mu_{4}-\mathrm{O}\right)\left(\mu_{4}-\mathrm{OH}\right)\left(\mu_{3}-\mathrm{OH}\right)_{8} "$ with $\mathrm{Ln}=\mathrm{Y}$ and $\mathrm{Ln}$ ' $\left.=\mathrm{Eu}\right)$. Structurally, this study shows that the biggest rare earth ion $\left(\mathrm{Eu}^{3+}\right)$ preferentially occupies the central $\mu_{4}-\mathrm{O}$ atom.

\subsection{Dodeca-nuclear motifs}

This dodeca-nuclear motif (" $\operatorname{Ln}_{12}\left(\mu_{3}-\mathrm{OH}\right)_{16}$ ") can be described as the cyclization of four cubane-like tetra-nuclear motifs that would share edges (Fig. 11). Compounds that exhibit this poly-nuclear core have been obtained with amino acids or EDTA as ligands [46, 49 , 157]. The formal charge of dodeca-nuclear cores is +20 . Halide ions that are encapsulated in the cavity (Fig. 11) insure the stability of the motif.

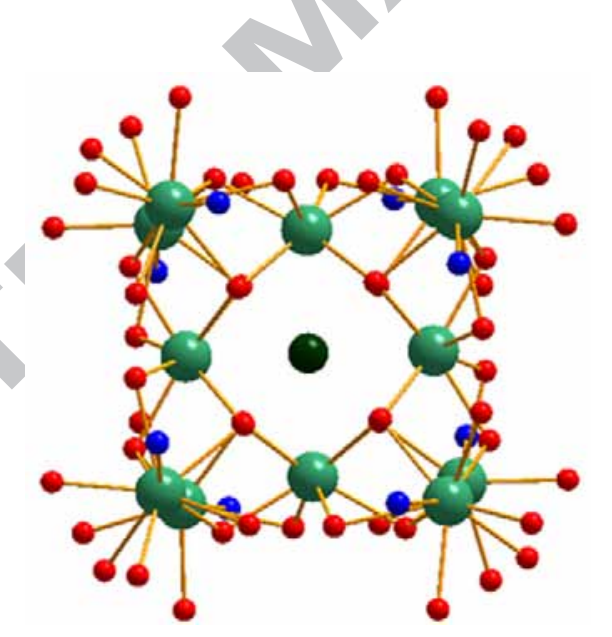

Fig. 11. Dodeca-nuclear motif " $\operatorname{Ln}_{12}\left(\mu_{3}-\mathrm{OH}\right)_{16}$ " $\left(\mathrm{h}=1.33\right.$ and $\left.3.5<\mathrm{d}_{\mathrm{Ln}-\mathrm{Ln}}(\AA)<3.8\right)$. Black ball symbolizes halide ion. Redrawn from reference [157]. Blue, red, dark and light green balls stand for nitrogen, oxygen, halide and lanthanide atoms respectively.

4.10. Tetradeca-nuclear motifs

Double sandglass-like tetradeca-nuclear motifs $\quad[61, \quad 158-160]$ (" $\mathrm{Ln}_{14}\left(\mu_{4}-\mathrm{OH}\right)_{2}\left(\mu_{3}-\mathrm{OH}\right)_{16}$ ") can be described as a central octahedral hexa-nuclear motif that 
would share two opposite vertices with two square-base pyramids (Fig. 12). The $\mu_{6}$-O central atom is not present at the center of the octahedron except for the coordination polymer reported in reference [159] in which tetradeca-nuclear complexes act as metallic nodes. The formal charge is +14 .

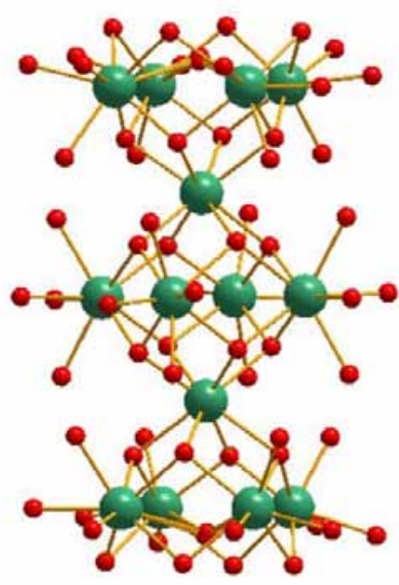

Fig. 12. Tetradeca-nuclear motif " $\operatorname{Ln}_{14}\left(\mu_{4}-\mathrm{OH}\right)_{2}\left(\mu_{3}-\mathrm{OH}\right)_{16} "\left(\mathrm{~h}=1.3\right.$ and $3.5<\mathrm{d}_{\text {Ln-Ln }}(\AA)<$ 3.9). Redrawn from reference [158]. Red and green balls stand for oxygen and lanthanide atoms respectively.

\subsection{Pentadeca-nuclear motifs}

Wheel-like pentadeca-nuclear motifs $\left(" \operatorname{Ln}_{15}\left(\mu_{3}-\mathrm{OH}\right)_{20} "\right)[157,158,161]$ can be described on the basis of five cubane-like tetra-nuclear motifs that would share vertices (Fig. 13). Halide ion located at the center of the wheel, insure the stability of the poly-nuclear core that have a +25 formal charge. 


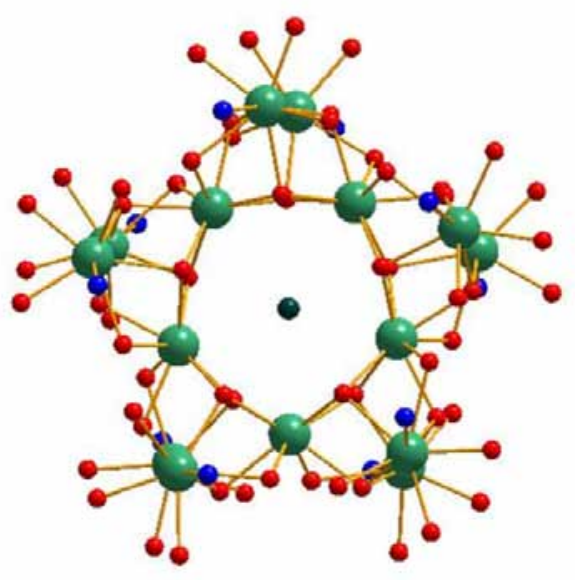

Fig. 13. Wheel-like pentadeca-nuclear motifs " $\operatorname{Ln}_{15}\left(\mu_{3}-\mathrm{OH}\right)_{20} "\left(\mathrm{~h}=1.33\right.$ and $3.6<\mathrm{d}_{\mathrm{Ln}-\mathrm{Ln}}(\AA)$ $<3.8$ ). Black ball symbolizes halide ion. Redrawn from reference [158]. Blue, red, dark and light green balls stand for nitrogen, oxygen, halide and lanthanide atoms respectively.

\subsection{Icosahexa-nuclear motifs}

To the best of our knowledge, this motif $\left(" \mathrm{Ln}_{26}\left(\mu_{3}-\mathrm{OH}\right)_{20}\left(\mu_{3}-\mathrm{O}\right)_{6} \mathrm{~A}_{9}\right.$ " where $\mathrm{A}=\mathrm{NO}_{3}{ }^{-}$ or $\mathrm{CO}_{3}{ }^{2-}$ ) has been reported only twice $[42,162]$. It can be described (Fig. 14) on the basis of five cubane-like tetra-nuclear motifs linked to each other by $\mathrm{NO}_{3}{ }^{-}$[42] or $\mathrm{CO}_{3}{ }^{2-}$ [162] bridges. Additionally six lanthanide ions intercalate between the tetra-nuclear motifs. At last, counter anion reinforces the stability of the poly-nuclear cores that act as nodes in an extended molecular framework with isonicotinate as ligand. The formal charge of the core is +37 . 


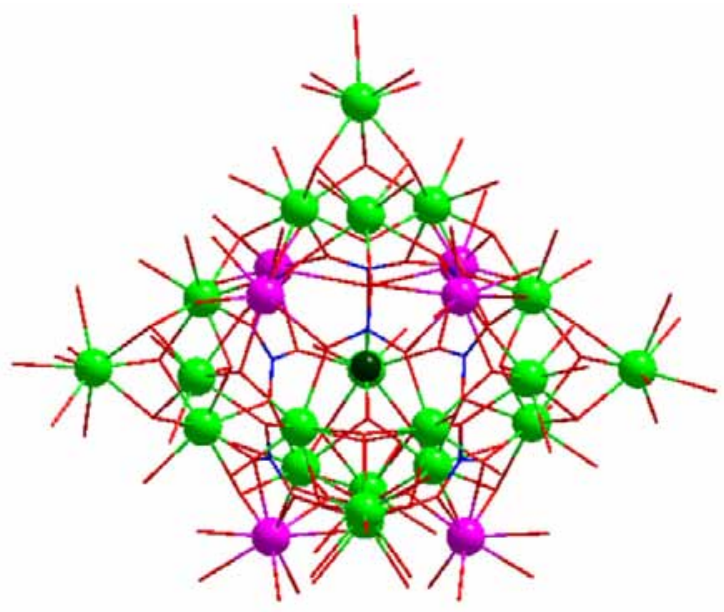

Fig. 14. Icosahexa-nuclear motif " $\operatorname{Ln}_{26}\left(\mu_{3}-\mathrm{OH}\right)_{20}\left(\mu_{3}-\mathrm{O}\right)_{6} \mathrm{~A}_{9}$ " with $\mathrm{A}=\mathrm{NO}_{3}^{-}(\mathrm{h}=1.2$ and $3.7<$ $\left.\mathrm{d}_{\text {Ln-Ln }}(\AA)<3.9\right)$. Black ball symbolizes nitrate ion. Lanthanide ions that belong to tetranuclear entities are drawn in green and intercalated ones in pink. Redrawn from reference [42].

\subsection{Poly-nuclear motifs with higher nuclearity}

Poly-nuclear motifs with very high nuclearity such as " $\operatorname{Ln}_{60}\left(\mu_{6}-\mathrm{CO}_{3}\right)_{8}\left(\mu_{3}-\mathrm{OH}\right)_{96}\left(\mu_{2^{-}}\right.$ $\mathrm{O})_{2} "$ [53], "Ln ${ }_{38} \mathrm{O}(\mathrm{OH})_{59}$ ", " $\mathrm{Ln}_{48} \mathrm{O}_{6}(\mathrm{OH})_{84} "$ [163] and " $\mathrm{Ln}_{104}\left(\mu_{3}-\mathrm{OH}\right)_{168}\left(\mu_{4}-\mathrm{O}\right)_{30}$ " [164] have also been reported. They all can be described on the basis of motifs of lower symmetries. For instance, $" \operatorname{Ln}_{60}\left(\mu_{6}-\mathrm{CO}_{3}\right)_{8}\left(\mu_{3}-\mathrm{OH}\right)_{96}\left(\mu_{2}-\mathrm{O}\right)_{2}$ " has been described on the basis of the sodalite structural type [165]. Therefore, it is characterized by the association of twenty-four cubanelike tetra-nuclear motifs. Hexagonal and cubic faces are constituted by $\operatorname{Ln}_{18}$ and $\operatorname{Ln}_{12}$ entities respectively (Fig. 15). The formal charge is +64 . This motif has been isolated as a complex with an amino acid as ligand. 


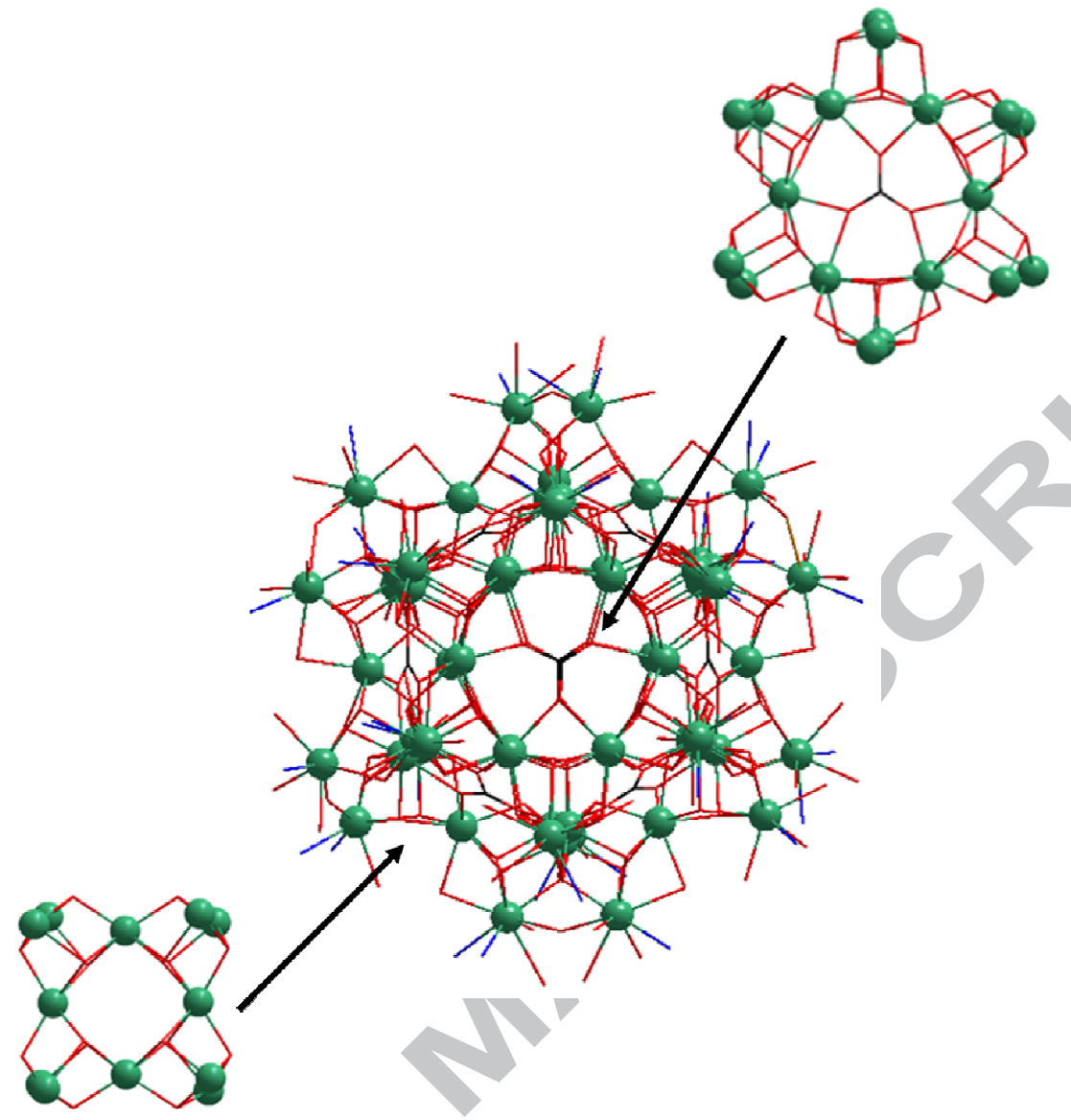

Fig. 15. Hexaconta-nuclear motifs " $\mathrm{Ln}_{60}\left(\mu_{6}-\mathrm{CO}_{3}\right)_{8}\left(\mu_{3}-\mathrm{OH}\right)_{96}\left(\mu_{2}-\mathrm{O}\right)_{2} "$ and organizations of the cubane-like motifs in $\mathrm{Ln}_{12}$ and $\mathrm{Ln}_{18}$ faces $\left(\mathrm{h}=1.67\right.$ and $\left.3.5<\mathrm{d}_{\mathrm{Ln}-\mathrm{Ln}}(\AA)<3.8\right)$. Redrawn from reference [53]. Green balls stand for lanthanide atoms.

These compounds illustrate the lanthanide ions ability to lead to compounds with very high nuclearity. Moreover, Gd-derivatives of high nuclearity compounds can also offer interesting perspectives as far as magneto-caloric effects are targeted [166].

From this brief survey it can be noticed that the only lanthanide based poly-nuclear complexes that can be used as previously isolated reactants for further chemistry, are the octahedral hexa-nuclear ones. 


\section{Synthesis and stability of the octahedral hexa-nuclear entities}

Octahedral hexa-nuclear lanthanide-based oxo-hydroxo complexes have often been obtained fortuitously in complexes or coordination polymers (Table 3).

Table 3

Some examples of hexa-nuclear-based coordination compounds obtained fortuitously.

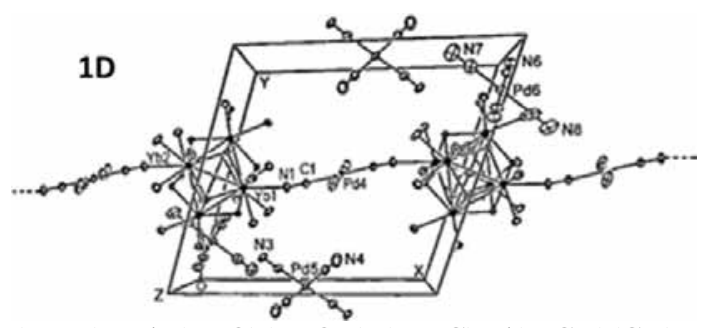

$\left[(\mathrm{DMF})_{16} \mathrm{Yb}_{6}\left(\mu_{6}-\mathrm{O}\right)\left(\mu_{3}-\mathrm{OH}\right)_{8}(\mu-\mathrm{NC}) \mathrm{Pd}(\mu-\mathrm{CN})(\mathrm{CN})_{2}\right]$. $\left[\mathrm{Pd}(\mathrm{CN})_{4}\right]_{3} .4 \mathrm{DMF}[139]$.

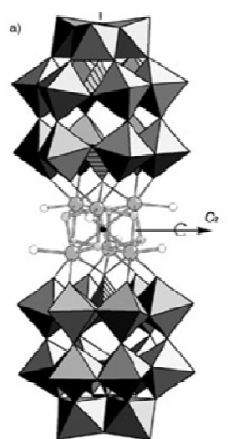

OD

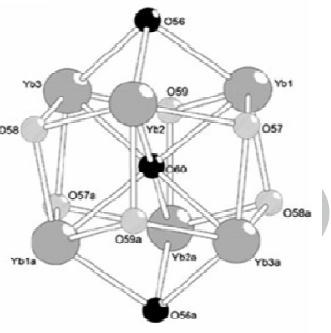

$\left[\mathrm{Yb}_{6}\left(\mu_{6}-\mathrm{O}\right)\left(\mu_{3}-\mathrm{OH}\right)_{6}\left(\mathrm{H}_{2} \mathrm{O}\right)_{6}\right] \alpha-\left[\mathrm{P}_{2} \mathrm{~W}_{15} \mathrm{O}_{56}\right]_{2}[132]$.
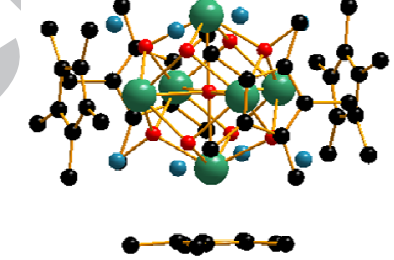

$\left[\left(\mathrm{Cp}^{*}\right)_{6} \mathrm{Sm}_{6}\left(\mu_{6}-\mathrm{O}\right)\left(\mu_{3}-\mathrm{OMe}\right)_{7.5}(\mathrm{I})_{0.5}\right]\left[\mathrm{K}(\mathrm{THF})_{6}\right][134]$.

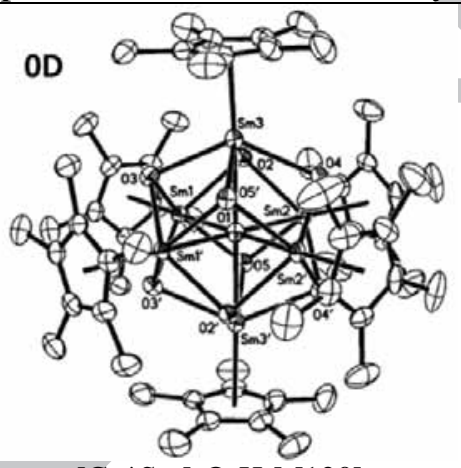

$\left.[\mathrm{Cp} * \mathrm{Sm}]_{6} \mathrm{O}_{9} \mathrm{H}_{6}\right][130]$.

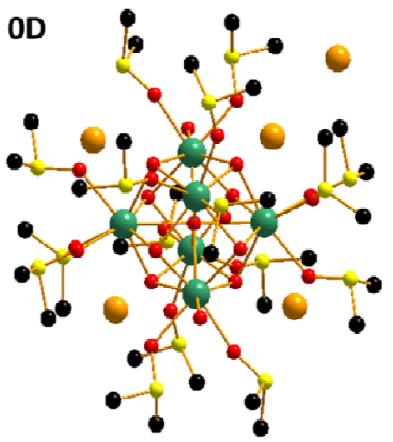

$\left[\mathrm{Y}_{6}\left(\mu_{6}-\mathrm{O}\right)\left(\mu_{3}-\mathrm{OH}\right)_{8}(\mathrm{DMSO})_{16-x}\left(\mathrm{H}_{2} \mathrm{O}\right)_{x}\right]\left[\mathrm{Cu}_{2} \mathrm{I}_{4}\right] 6[\mathrm{I}] /$ $2\left[\mathrm{CuI}_{3}\right][\mathrm{I}]\left[\mathrm{I}_{3}\right][133]$.

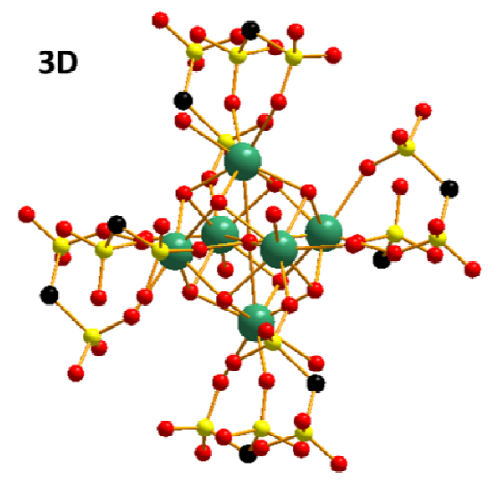

$\left[\mathrm{Yb}_{6}\left(\mu_{6}-\mathrm{O}\right)\left(\mu_{3}-\mathrm{OH}\right)_{8}\left(\mathrm{H}_{2} \mathrm{O}\right)_{6}\left(\mathrm{CH}_{2} \mathrm{O}_{6} \mathrm{~S}_{2}\right)_{4}\right]_{\infty}[40]$. 


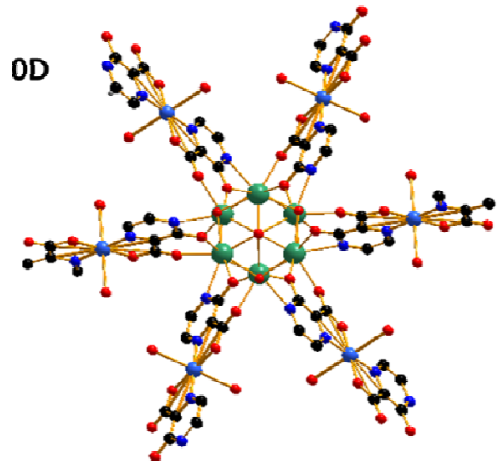

$\left[\mathrm{Ln}_{2} \mathrm{Cu}\left(\mu_{6}-\mathrm{O}\right)_{1 / 6}\left(\mu_{3}-\mathrm{OH}\right)_{2 / 3}\left(\mu_{3}-\mathrm{OH}\right)_{2}(\mathrm{hpzc})_{2}\left(\mathrm{H}_{2} \mathrm{O}\right)_{2}\right]$ $\cdot 2 \mathrm{H}_{2} \mathrm{O}$ with $\mathrm{Ln}=\mathrm{Dy}$, Ho, Er and hpzc $=3$-hydroxypyrazine-2-carboxylate [140].

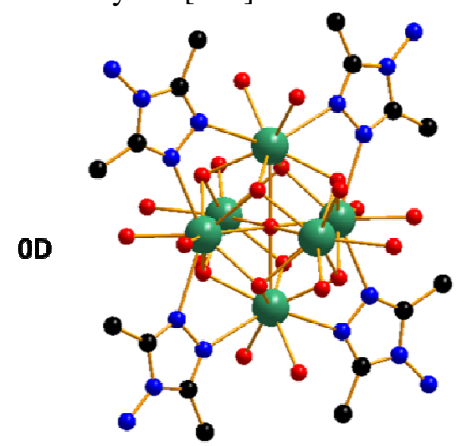

$\left[\operatorname{Ln}_{6}\left(\mu_{6}-\mathrm{O}\right)\left(\mu_{3}-\mathrm{OH}\right)_{8}(\mathrm{~L})_{4}\left(\mathrm{H}_{2} \mathrm{O}\right)_{14}\right] \mathrm{Cl}_{8} \cdot 2 \mathrm{~L} \cdot 6 \mathrm{H}_{2} \mathrm{O} \quad$ with $\mathrm{Ln}=\mathrm{Er}, \mathrm{Ho}, \mathrm{Dy}, \mathrm{Gd}, \mathrm{Tb}$ and $\mathrm{L}=4$-amido-3,5dimethyl-1,2,4-triazole [142].

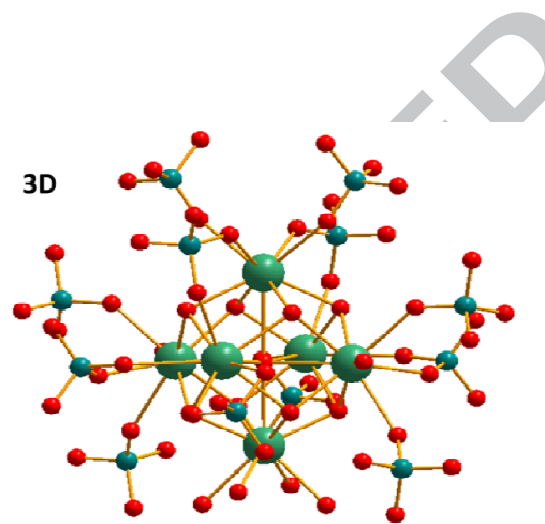

$\left\{\left[\mathrm{Ln}_{6}\left(\mu_{6}-\mathrm{O}\right)\left(\mu_{3}-\mathrm{OH}\right)_{8}\left(\mu_{4}-\mathrm{ClO}_{4}\right)_{4}\left(\mathrm{H}_{2} \mathrm{O}\right)_{6}\right](\mathrm{OH})_{4}\right\}_{\infty}$ with $\mathrm{Ln}=\mathrm{Gd}$, Dy [143].

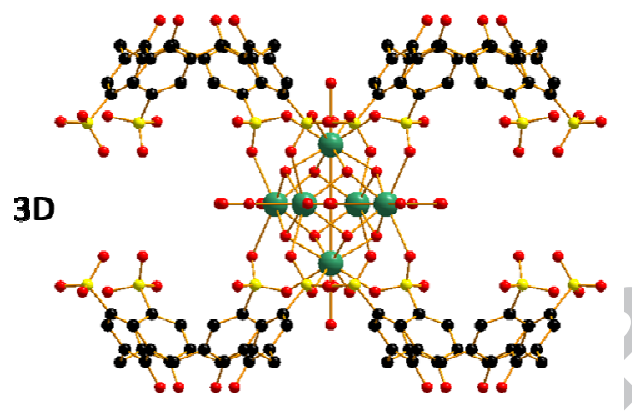

$\left[\mathrm{Ln}_{6}\left(\mu_{6}-\mathrm{OH}\right)\left(\mu_{3}-\mathrm{OH}\right)_{8}\left(\mathrm{H}_{2} \mathrm{O}\right)_{8}(\mathrm{HL})(\mathrm{L})\right]$ with $\mathrm{Ln}=\mathrm{Pr}, \mathrm{Nd}$, $\mathrm{Yb}$ and $\mathrm{L}=\mathrm{p}$-sulfonatocalix[4] arene [141].

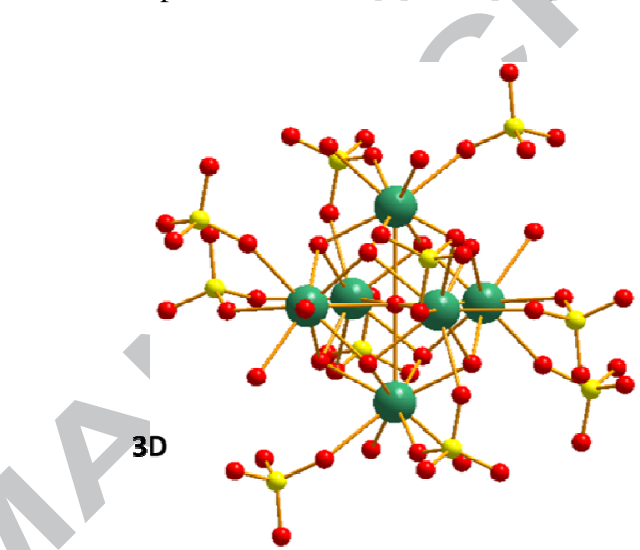

$\left[\mathrm{Eu}_{6}\left(\mu_{6}-\mathrm{O}\right)\left(\mu_{3}-\mathrm{OH}\right)_{8}\left(\mathrm{H}_{2} \mathrm{O}\right)_{6}\left(\mathrm{SO}_{4}\right)_{4}\right]_{\infty}[41]$

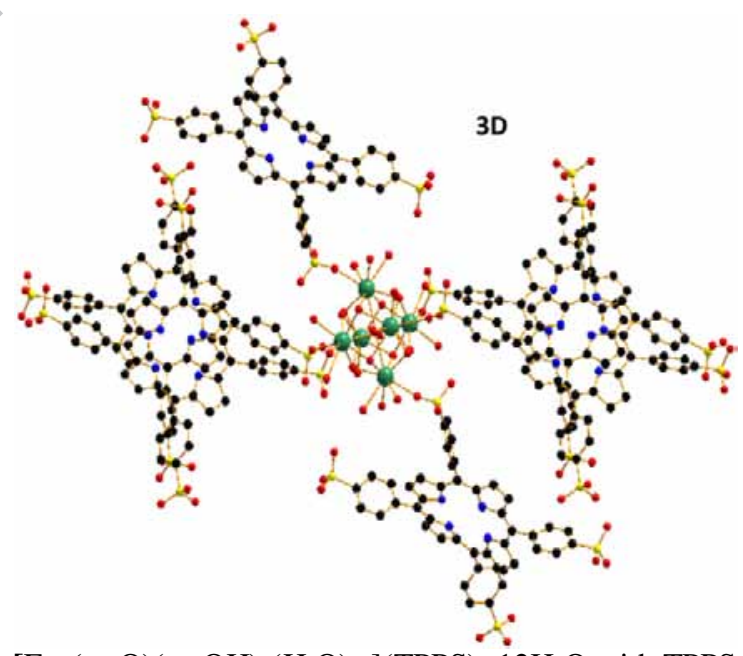

$\left[\mathrm{Eu}_{6}\left(\mu_{6}-\mathrm{O}\right)\left(\mu_{3}-\mathrm{OH}\right)_{8}\left(\mathrm{H}_{2} \mathrm{O}\right)_{14}\right](\mathrm{TPPS})_{2} \cdot 12 \mathrm{H}_{2} \mathrm{O}$ with TPPS $=5,10,15,20$-tetrakis(4-sulfonato-phenyl)porphyrin

Lanthanide-based hexa-nuclear complexes have also been obtained according to the controlled hydrolysis synthesis defined previously [46, 47, 78, 79]. In this case, to a concentrate aqueous solution of lanthanide perchlorate that contained an amino acid (tyrosine 
or L-serine) as ancillary ligand, a dilute aqueous solution of sodium hydroxide was carefully added. The addition was realized at $100{ }^{\circ} \mathrm{C}$ until precipitation occurred. The mixture was filtered and the filtrate allowed to slowly evaporate leading to single crystals of $\left[\mathrm{Ln}_{6}\left(\mu_{6}-\mathrm{O}\right)\left(\mu_{3}-\mathrm{OH}\right)_{8}\left(\mathrm{H}_{2} \mathrm{O}\right)_{24}\right]\left(\mathrm{ClO}_{4}\right)_{8} \cdot 4 \mathrm{H}_{2} \mathrm{O}(\mathrm{Ln}=\mathrm{Nd}, \mathrm{Gd})$ (Fig. 16).

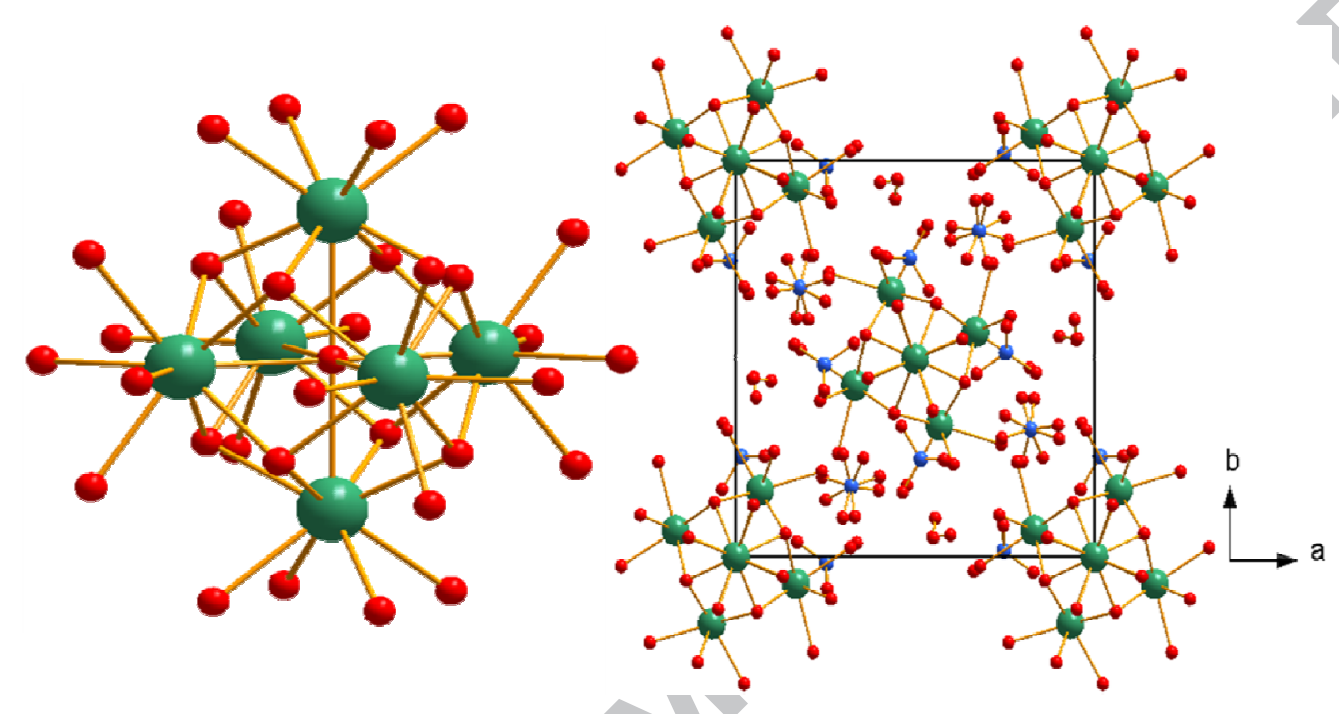

Fig. 16. Left: Projection view of the complex $\left[\mathrm{Nd}_{6}\left(\mu_{6}-\mathrm{O}\right)\left(\mu_{3}-\mathrm{OH}\right)_{8}\left(\mathrm{H}_{2} \mathrm{O}\right)_{24}\right]^{8+}$. Right: Projection view along the $c$-axis of an extended unit cell of $\left[\mathrm{Nd}_{6}\left(\mu_{6}-\mathrm{O}\right)\left(\mu_{3}-\mathrm{OH}\right)_{8}\left(\mathrm{H}_{2} \mathrm{O}\right)_{24}\right]\left(\mathrm{ClO}_{4}\right)_{8} \cdot 4 \mathrm{H}_{2} \mathrm{O}$. Redrawn from reference [79]. Blue, red and green balls stand for nitrogen, oxygen and lanthanide atoms respectively.

In this crystal structure, there are four coordination water molecules per $\mathrm{Nd}^{3+}$ ion and the perchlorate ions are located in the inter-complexes space. Therefore, the formal charge of the complexes is +8 and they are very sensitive to hydrolysis even in organic solvents such as acetone, THF or $\mathrm{CH}_{3} \mathrm{CN}$ in which they present weak solubility. In addition, perchlorate salts synthesis is hazardous and this synthetic pathway requires the use of ancillary ligands for the hydrolysis control. That is why, despite its neatness, this synthetic pathway never permits the use of the hexa-nuclear complexes as reactants. 
For completeness, it must be noticed that complexes with general chemical formula $\left[\mathrm{Ln}_{6}\left(\mu_{6}-\mathrm{O}\right)\left(\mu_{3}-\mathrm{OH}\right)_{8}\left(\mathrm{H}_{2} \mathrm{O}\right)_{24}\right]^{8+}$ with $\mathrm{Ln}=\mathrm{La}$ [137], Nd [136], Eu-Dy [167] and Y [168] can also be obtained with iodine as counter anions.

A second route that follows the direct hydrolysis strategy has been used. It uses lanthanide nitrate as starting materials and does not require ancillary ligands. This route leads to several different compounds that differ from each other by their hydration rate. Complexes obtained have general chemical formula $\left[\mathrm{Ln}_{6}\left(\mu_{6}-\mathrm{O}\right)\left(\mu_{3}-\mathrm{OH}\right)_{8}\left(\mathrm{H}_{2} \mathrm{O}\right)_{\mathrm{n}}\left(\mathrm{NO}_{3}\right)_{6}\right] 2 \mathrm{NO}_{3} \cdot \mathrm{mH}_{2} \mathrm{O}$ where $\mathrm{n}$ and $\mathrm{m}$ are the number of coordination and crystallization water molecules respectively. This synthetic pathway has first been reported by Zak, Unfried and Giester in 1994 [72]. In this paper, complexes with $\mathrm{n}=12$ and $\mathrm{m}=4$ for $\mathrm{Ln}=\mathrm{Y}$ or $\mathrm{Yb}$ and $\mathrm{n}=12$ and $\mathrm{m}$ $=5$ for $\mathrm{Ln}=\mathrm{Gd}$ are described. In 1997, the authors completed their study and described compounds that present $\mathrm{n}=12$ and $\mathrm{m}=4$ for $\operatorname{Ln}=\mathrm{Er}, \mathrm{n}=12$ and $\mathrm{m}=5$ for $\operatorname{Ln}=$ Dy and $\mathrm{n}=$ 12 and $\mathrm{m}=6$ for $\mathrm{Ln}=\mathrm{Sm}[69$ ]. Recently, these authors published another article that extends the series [68]. All these compounds present similar crystal structures in which lanthanide ions occupy the vertices of a quasi-perfect octahedron, a $\mu_{6}-\mathrm{O}$ atom is located at the center of the octahedron whose each face is capped by a $\mu_{3}-\mathrm{OH}$ group. Additionally, each lanthanide ion is bound by a bi-dentate nitrate ion and two coordination water molecules (Fig. 17).

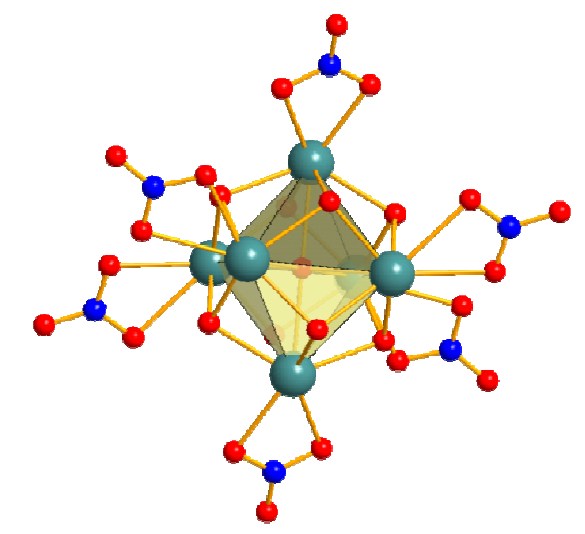

Fig. 17. Projection view of $\left[\mathrm{Ln}_{6}\left(\mu_{6}-\mathrm{O}\right)\left(\mu_{3}-\mathrm{OH}\right)_{8}\left(\mathrm{H}_{2} \mathrm{O}\right)_{\mathrm{n}}\left(\mathrm{NO}_{3}\right)_{6}\right]$. Coordination water molecules have been omitted for clarity. Redrawn from reference [169]. Blue, red and green balls stand for nitrogen, oxygen and lanthanide atoms respectively. 
Coordinated bi-dentate nitrates improve the stability of the hexa-nuclear complexes whose global charge is reduced to +2 . Actually the complexes obtained from lanthanide nitrates are less sensitive to hydrolysis than those obtained from lanthanide perchlorates.

Unfortunately the syntheses described by Unfried et al. were delicate and difficult to reproduce. Indeed, octahedral hexa-nuclear complexes have an hydration rate equal to 1.67 which is very close to that of insoluble and very stable polymeric species such as $\mathrm{Ln}(\mathrm{OH})_{2}\left(\mathrm{NO}_{3}\right)$ [170], $\mathrm{LnONO}_{3}[77]$ or $\mathrm{Ln}(\mathrm{OH})_{3}$ [34] that present hydration rates of 2 or 3 , respectively. This drawback has been overcome in 2005 and a rationalized synthetic method, that allows the synthesis in reasonable yields of hexa-nuclear complexes with any lanthanide ion comprised between $\operatorname{Pr}^{3+}$ and $\mathrm{Lu}^{3+}$, has been described $[76,80]$. In this method, hydrolysis is realized in an ethanol/water mixture medium. Typically, to a concentrated $\left(1 \mathrm{~mol} . \mathrm{L}^{-1}\right.$ to 1.5 mol. $\left.\mathrm{L}^{-1}\right)$ ethanolic solution of lanthanide nitrate, a dilute aqueous solution $\left(0.5 \mathrm{~mol} . \mathrm{L}^{-1}\right)$ of sodium hydroxide is added drop by drop under vigorous stirring. The addition is stopped when the precipitate that forms at each drop does not disappear anymore. Hexa-nuclear complexes form in a very narrow $\mathrm{pH}$ range (Fig. 18). The $\mathrm{pH}$ range as well as the yield of the synthesis highly depend on the lanthanide ion that is considered. 


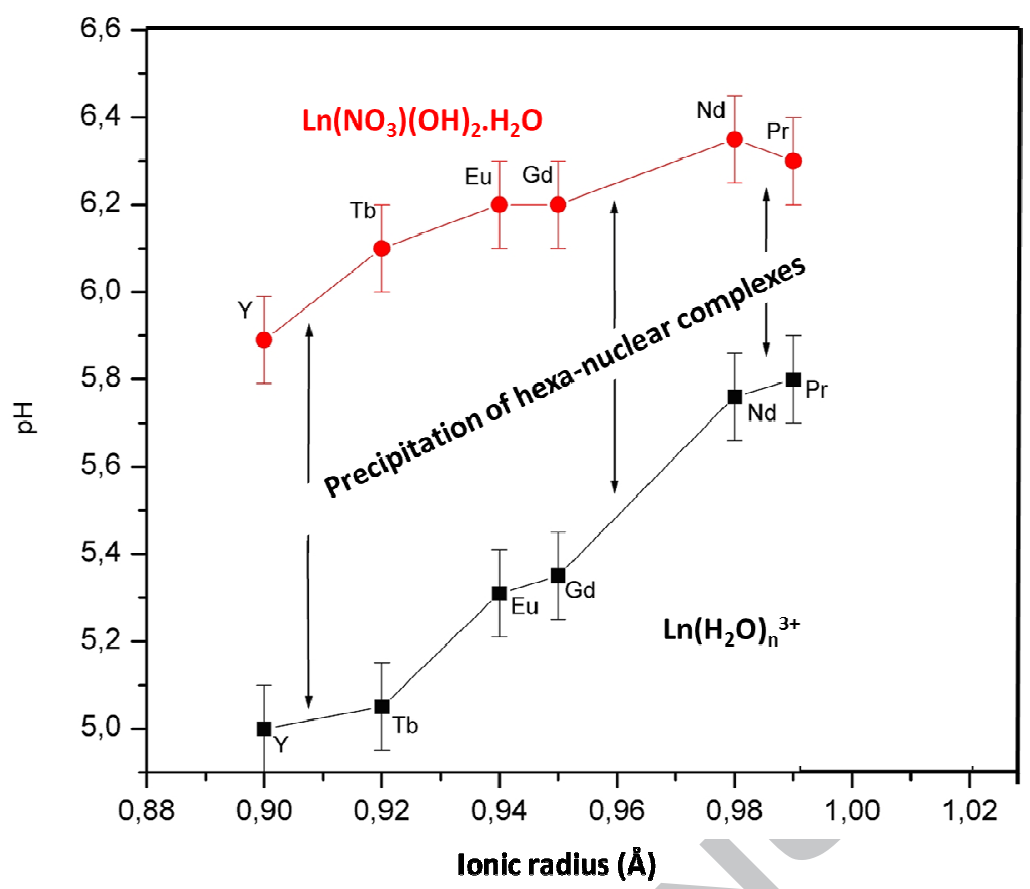

Fig. 18. pH range in which hexa-nuclear complexes are obtained versus ionic radius of the involved lanthanide ion. Redrawn from reference [171].

This method has also led to the Ce(III)-based octahedral hexa-nuclear complex [138] which has been identified on the basis of its X-ray powder diffraction diagram. Indeed the stable +IV oxidation state of the cerium, which is more sensitive to hydrolysis $[172,173]$, makes this synthesis delicate and no single-crystal has been obtained with $\mathrm{Ce}(\mathrm{III})$.

As mentioned above, all the octahedral hexa-nuclear complexes present similar molecular structures and the differences observed in the solid state are mainly related to their hydration rates. Octahedral hexa-nuclear complexes crystal structures that have been reported in the literature so far are summarized in Table 4. 


\section{Table 4}

Crystal structures of octahedral hexa-nuclear complexes versus hydration rate.

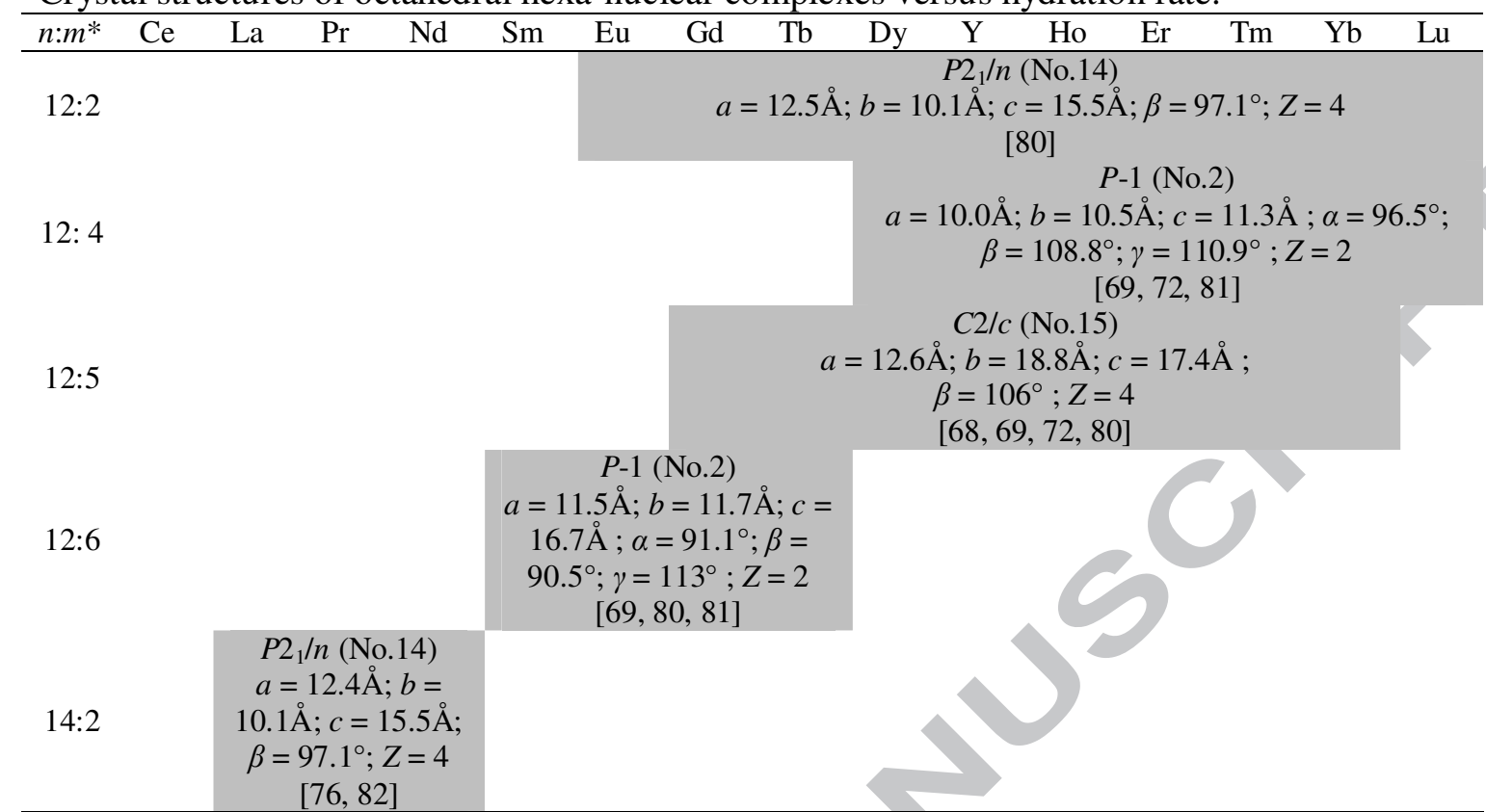

* $n$ is the number of coordination water molecule. $m$ is the number of crystallization water molecules.

When $n$ is equal to 12 , all lanthanide ions are nine-coordinated and two coordination water molecules enter the coordination sphere. When $n$ is equal to 14 , two lanthanide ions in apical positions are ten-coordinated and three coordination water molecules contribute to their coordination sphere.

Dehydration of these phases leads to two more phases with $(n, m)$ equal to $(6,0)$ and $(0,0)$, respectively. Both crystal structures have been solved on the basis of powder X-ray diffraction diagrams $[138,171]$. In the first crystal structure, which has been solved on the basis of the Ho-containing microcrystalline powder, there is no crystallization water molecule anymore and only one coordination water molecule per lanthanide ion. Lanthanide ions are thus eight-coordinated by eight oxygen atoms that form a distorted bi-capped trigonal prism. The molecular structure of the octahedral hexa-nuclear complex remains almost unchanged. 
This phase is obtained at temperature that varies between $90{ }^{\circ} \mathrm{C}$ and $130{ }^{\circ} \mathrm{C}$ according to the considered lanthanide ion (Fig. 19).

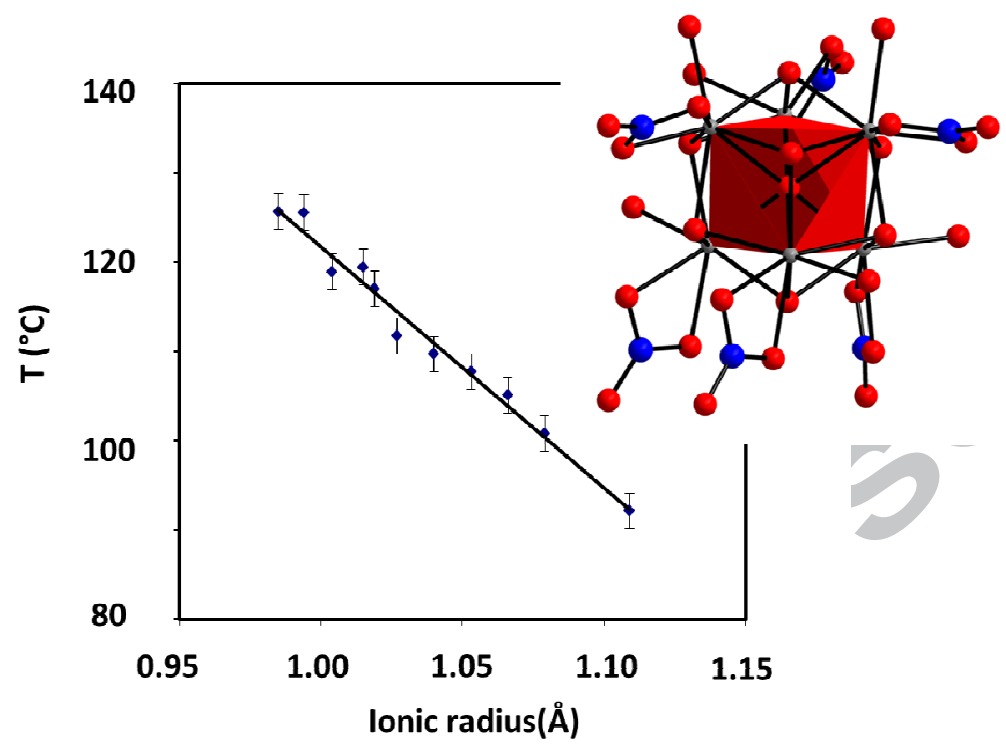

Fig. 19: Temperature at which the crystallographic phase $(6,0)$ is obtained versus ionic radius of the involved lanthanide ion. In inset: projection view of $\left[\mathrm{Ho}_{6}\left(\mu_{6}-\mathrm{O}\right)\left(\mu_{3}-\mathrm{OH}\right)_{8}\left(\mathrm{H}_{2} \mathrm{O}\right)_{6}\left(\mathrm{NO}_{3}\right)_{6}\right]$. Cell parameters: $a=13.951 \AA, b=10.227 \AA, c=12.949$ $\AA$, $\beta=88.85^{\circ}, V=1847.2 \AA^{3}$. Redrawn from reference [138].

This crystallographic phase can be completely dehydrated leading to an anhydrous $(0,0)$ phase. Crystal structure of these compounds with general chemical formula $\left[\mathrm{Ln}_{6}\left(\mu_{6}-\mathrm{O}\right)\left(\mu_{3}-\mathrm{OH}\right)_{8}\left(\mathrm{NO}_{3}\right)_{8}\right]_{\infty}$ has been solved on the basis of the Y-containing microcrystalline powder. It crystallizes in the triclinic system, space group $P-1$ (No. 2) with $a$ $=10.394 \AA, b=9.507 \AA, c=9.373 \AA, \alpha=115.2^{\circ} ; \beta=119.1^{\circ} ; \gamma=97.35^{\circ}$ and $V=663.3 \AA^{3}$.

The crystal structure can be described as the superimposition of 1D chains of octahedral hexanuclear complexes (Fig. 20) bind to each other by nitrate groups that link lanthanide ions from neighboring complexes in a bi-dentate manner on the one hand and in a mono-dentate manner on the other hand. 


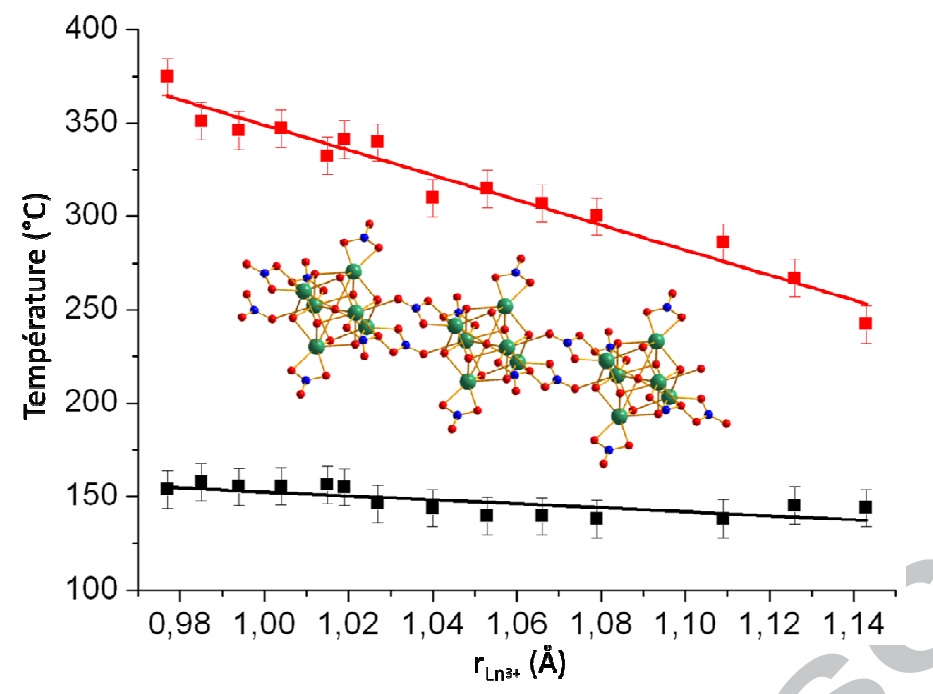

Fig. 20. Thermal stability of the $(0,0)$ anhydrous phase versus the involved lanthanide ion. In inset: Projection view of a chain of octahedral hexa-nuclear complexes in $\left[\mathrm{Y}_{6}\left(\mu_{6}-\mathrm{O}\right)\left(\mu_{3}-\mathrm{OH}\right)_{8}\left(\mathrm{NO}_{3}\right)_{8}\right]_{\infty}$. Redrawn from reference [138].

This anhydrous phase which is stable over a quite large temperature range (Fig. 20) can reversibly binds water when exposed to wet atmosphere leading to hydrated phases. Only hydration makes these crystalline phases different from each other and therefore it is possible to switch from one to another by simple hydration/de-hydration processes (Fig. 21). 
$\left[\mathrm{Ln}_{6} \mathrm{O}(\mathrm{OH})_{6}\left(\mathrm{NO}_{3}\right)_{6}\left(\mathrm{H}_{2} \mathrm{O}\right)_{n} \cdot 2 \mathrm{NO}_{3} \cdot \mathrm{mH}_{2} \mathrm{O}\right]$

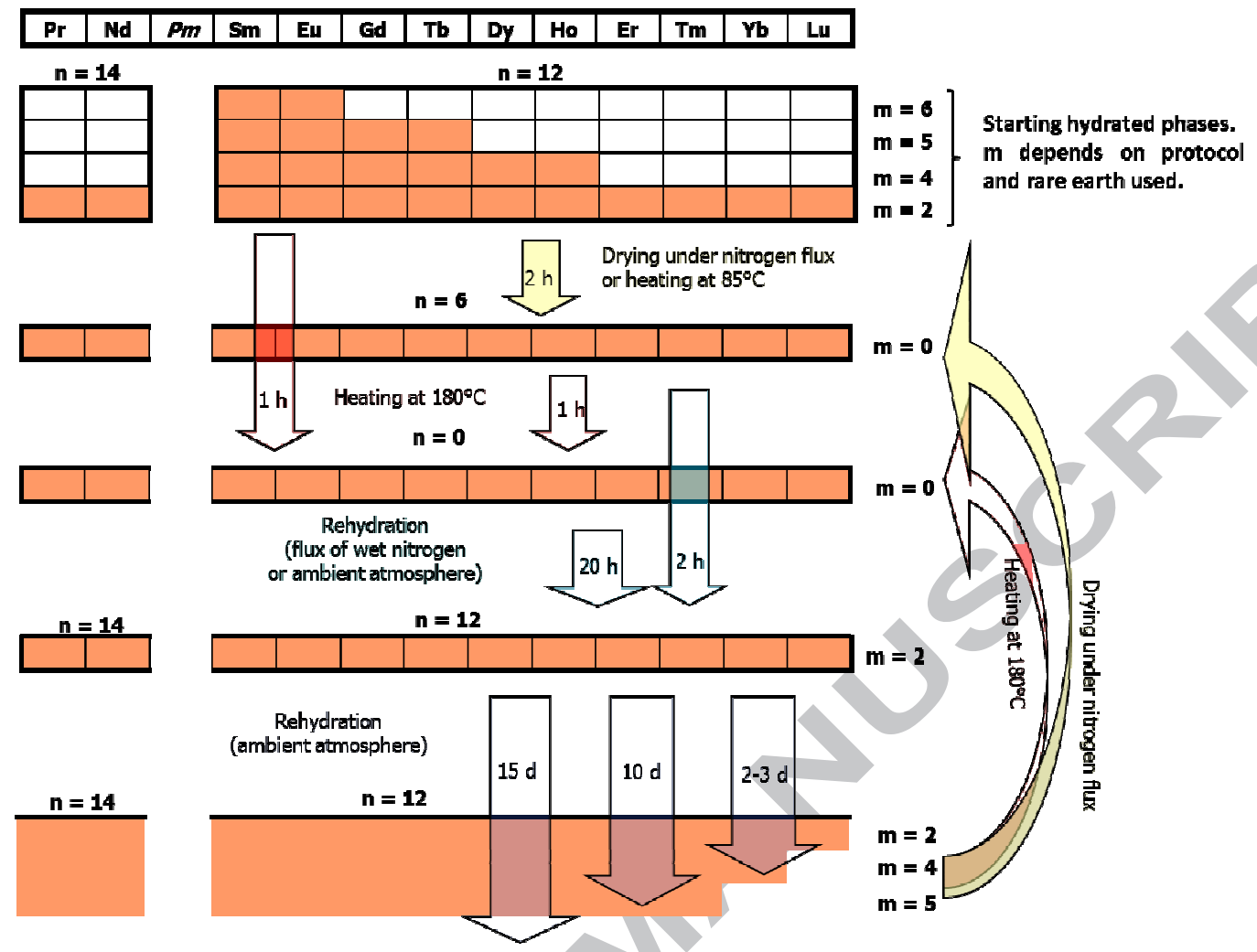

Fig. 21. Relationships between the different crystalline phases of the octahedral hexa-nuclear complexes. Redrawn from reference [138].

On the one hand, these hydration/de-hydration processes constitute an asset because they allow one to easily obtain one or another phase. On the other hand, they constitute a drawback because they make difficult the preservation of pure samples without extremely rigorous control of the atmosphere moisture.

From a luminescence point of view, these complexes exhibit sizeable but weak emission properties in the solid state (Fig. 22 and Table 5) [145]. 


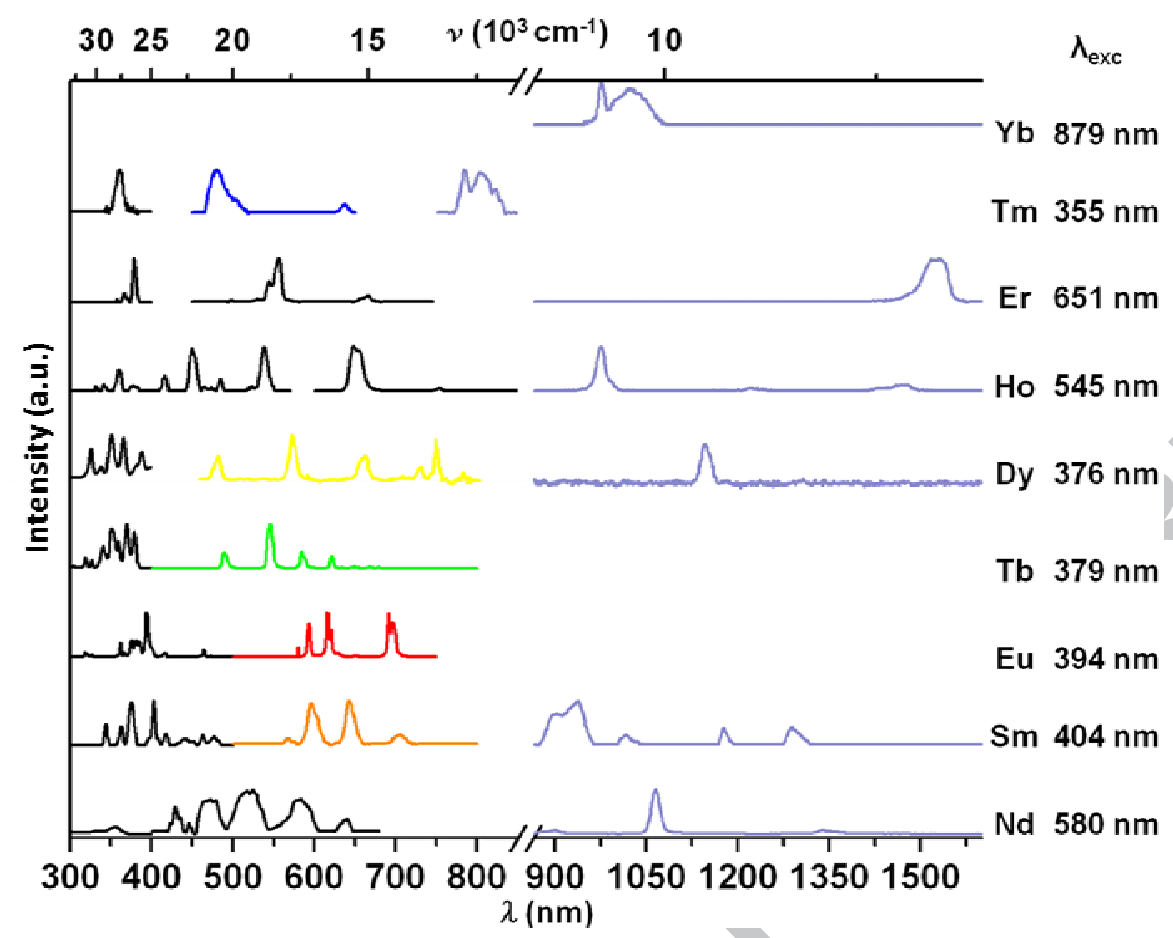

Fig. 22. Normalized solid state excitation and emission spectra for $\left[\mathrm{Ln}_{6} \mathrm{O}(\mathrm{OH})_{8}\left(\mathrm{NO}_{3}\right)_{6}\left(\mathrm{H}_{2} \mathrm{O}\right)_{n}\right] \cdot 2 \mathrm{NO}_{3} \cdot 2 \mathrm{H}_{2} \mathrm{O}$ with $n=12$ for $\mathrm{Ln}=\mathrm{Sm}-\mathrm{Lu}$ plus $\mathrm{Y}$ and $n=14$ for $\mathrm{Ln}$ $=\mathrm{Nd}$.

Table 5

Solid state intrinsic quantum yields and observed lifetimes for $\left[\mathrm{Ln}_{6} \mathrm{O}(\mathrm{OH})_{8}\left(\mathrm{NO}_{3}\right)_{6}\left(\mathrm{H}_{2} \mathrm{O}\right)_{12}\right] \cdot 2 \mathrm{NO}_{3} \cdot 2 \mathrm{H}_{2} \mathrm{O}$ for $\mathrm{Ln}=\mathrm{Sm}, \mathrm{Eu}, \mathrm{Tb}, \mathrm{Dy}$.

\begin{tabular}{llll}
\hline $\mathrm{Ln}$ & $\lambda_{\mathrm{exc}}(\mathrm{nm})$ & $Q_{L n}^{L n}(\%)$ & $\tau_{\text {obs }}(\mathrm{ms})$ \\
\hline $\mathrm{Sm}$ & 404 & $0.14(2)$ & $6.8(1) .10^{-3}$ \\
$\mathrm{Eu}$ & 394 & $7.6(7)$ & $0.19(2)-0.22(2)^{*}$ \\
$\mathrm{~Tb}$ & 379 & $29(3)$ & $0.74(7)$ \\
$\mathrm{Dy}$ & 376 & $0.31(3)$ & $9.2(1) .10^{-3}$ \\
\hline
\end{tabular}

* Measured at $77 \mathrm{~K}$

Water provokes rapid hydrolysis of these complexes. Therefore they must be used in dry organic solvents. Their solubility is extremely low in non-polar organic solvent and hydrolysis rapidly occurs in highly polar organic solvent such as DMF, THF or DMSO. Therefore acetonitrile or alcohols constitute a good compromise between stability and solubility [171] (Table 6). 


\section{Table 6}

Solubility and stability of an Er-based hexa-nuclear complex in various dry organic solvents.

\begin{tabular}{lcl}
\hline Solvent & Solubility at $25^{\circ} \mathrm{C}\left(\mathrm{g} \mathrm{L}^{-1}\right)$ & Stability at $25^{\circ} \mathrm{C}$ \\
\hline DMSO & 21.0 & $1-2$ hours \\
DMF & 17.5 & $1-2$ hours \\
propan-2-one & 11.0 & $1-2$ hours \\
Ethanol & 3.5 & $1-2$ hours \\
THF & 3.5 & $1-2$ hours \\
propan-1-ol & 2.5 & $2-3$ days \\
butan-1-ol & 3.0 & $2-3$ days \\
butan-2-ol & 3.0 & Several months \\
acetonitrile & 3.0 & Several months \\
chloro-methane & $<0.1$ & Several months \\
di-chloro-methane & $<0.1$ & Several months \\
methyl-benzene & $<0.1$ & Several months \\
benzene & $<0.1$ & Several months \\
Ethylene glycol & 45 & Several months \\
\hline
\end{tabular}

Table 6 clearly shows that ethylene glycol plays a particular role. Indeed it has been demonstrated that, in poly-ol solvents, octahedral hexa-nuclear complexes do not dissolve but form some colloidal nano-aggregates. These nano aggregates have been characterized and a structural model proposed [145] (Fig. 23). Luminescent properties of the octahedral hexanuclear complexes observed in the solid state are preserved. Moreover, in these nanoaggregates, neighboring octahedral hexa-nuclear complexes have been estimated to be about $10 \AA$ far from each other. This implies a very low energy transfer between complexes and makes possible the preparation of liquid mixtures with anticipated color emission by color addition strategy (Fig. 23). 

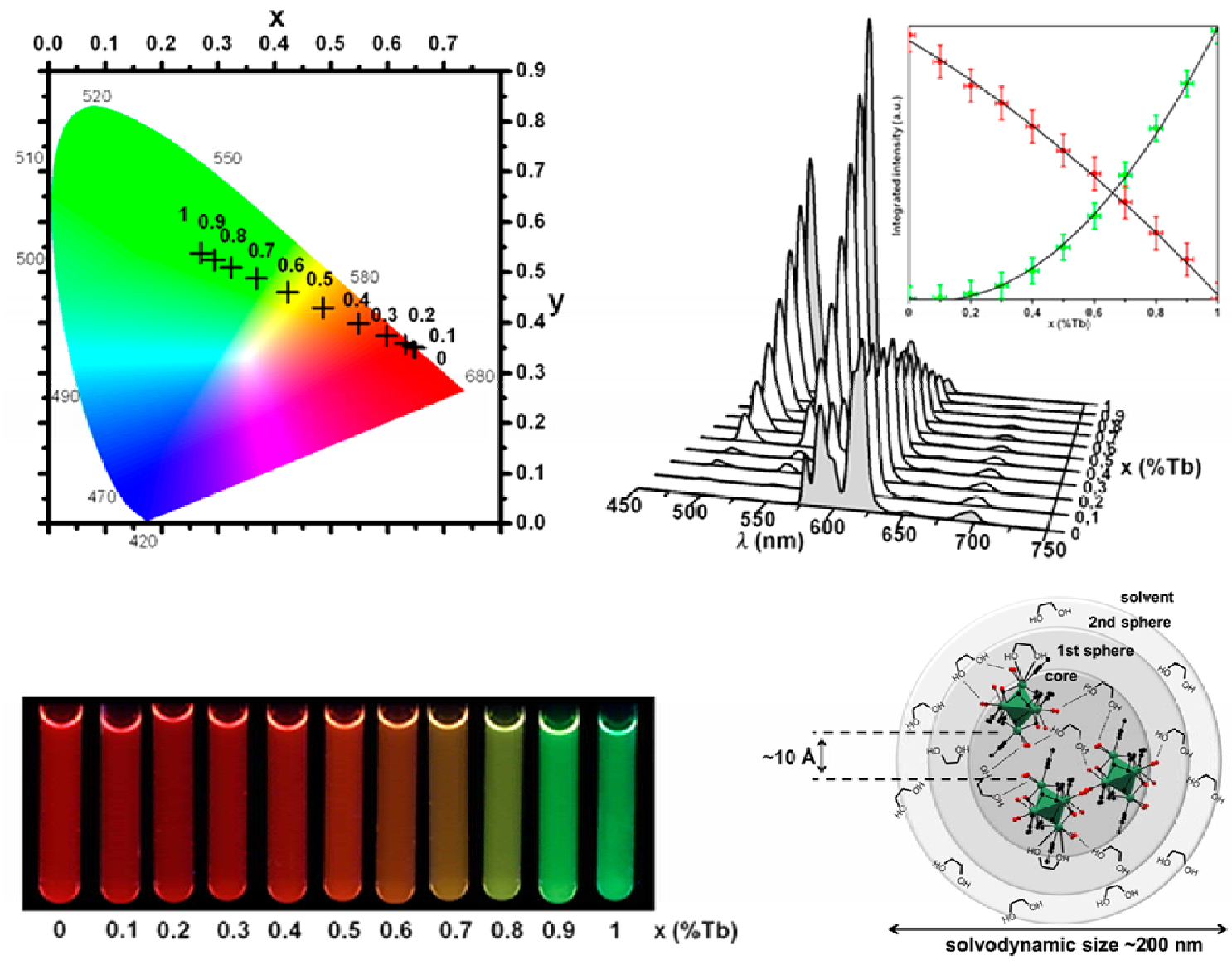

Fig. 23. Colorimetric coordinates under UV irradiation (top left), pictures under UV irradiation (bottom left) and emission spectra (in inset: Integrated intensities of $\mathrm{Tb}$ in green and $\mathrm{Eu}$ in red) of mixtures of nano-aggregates of $\mathrm{Tb}$ - and Eu-based hexa-nuclear complexes versus Tb-based complexes percent. Structural model suggested for nano-aggregates of octahedral hexa-nuclear complexes in ethylene glycol (bottom right). Reproduced from reference [145].

These solutions of nano-aggregates are stable over a long time but present no-antenna effect and therefore it is not possible to excite both the Eu- and the Tb-based hexa-nuclear complexes at a single excitation wavelength. This drawback has been overcome by using 2hydroxy-benzyl-alcohol instead of ethylene glycol and a sizeable enhancement of the luminescence of the solutions was observed. 
By simply replacing, in the rationalized synthetic process described above, the ethanolic solution of a single lanthanide nitrate by an ethanolic solution of a mixture of lanthanide nitrates, hetero-hexa-nuclear complexes can also be prepared [169]. Powder X ray diffraction patterns demonstrate that the crystal structure is similar to that of the homo-hexanuclear complexes. ${ }^{89} \mathrm{Y}$ CPMAS NMR spectroscopy has been realized on a series of heterohexa-nuclear complexes that contained both $\mathrm{Y}^{3+}$ and $\mathrm{Lu}^{3+}$ ions $\left(\left[\mathrm{Y}_{6-6 x} \mathrm{Lu}_{6 x} \mathrm{O}(\mathrm{OH})_{8}\left(\mathrm{NO}_{3}\right)_{6}\left(\mathrm{H}_{2} \mathrm{O}\right)_{12}\right] \cdot 2 \mathrm{NO}_{3} \cdot 2 \mathrm{H}_{2} \mathrm{O}\right.$ with $\left.0 \leq x \leq 1\right)$. It strongly supports the assumption of a random distribution of both lanthanide ions over the six available metallic sites. Indeed, whereas the three different contributions of the three crystallographically independent $\mathrm{Y}^{3+}$ appear in the pure yttrium derivative $(x=0)$, only on peak is observed in the hetero-nuclear compounds $(x=0.1)$ which indicates that all the $\mathrm{Y}^{3+}$ ions are equivalent as far as substitution by $\mathrm{Lu}^{3+}$ is concerned (Fig. 24). Therefore, hetero-hexa-nuclear complexes powders do not contain a single molecular entity but a mixture of several different complexes (Fig. 24). This constitutes a serious drawback as far as study of isolated molecular species is targeted because several different species contribute to the observed physical properties. On the opposite, it can be less disadvantageous if many poly-nuclear complexes are associated and only an average response is aimed. 

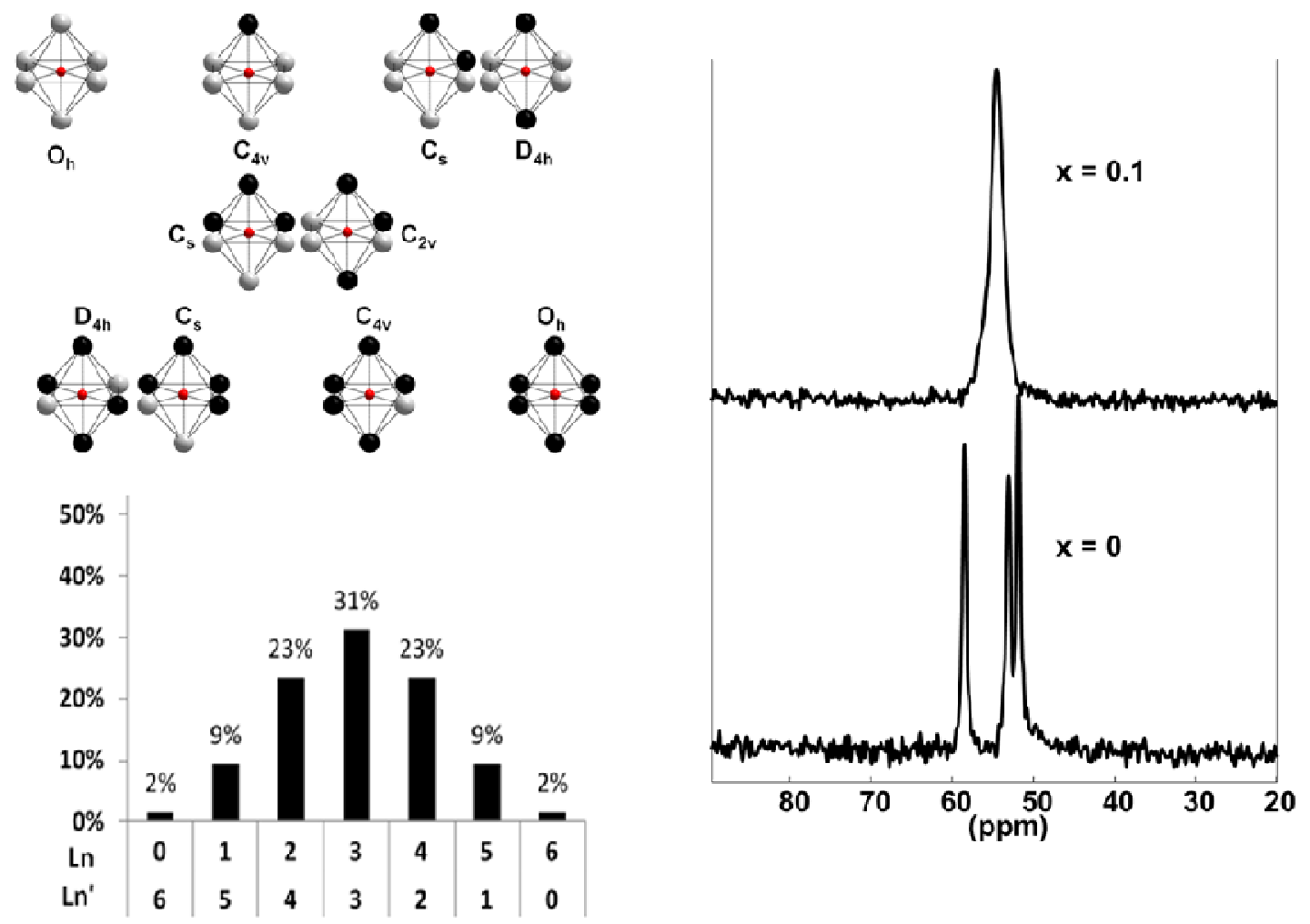

Fig. 24. Top left: Possible octahedral configurations for two lanthanides ions and their local symmetry. Bottom left: Relative abundance of the different hexa-nuclear complexes obtained from an equi-molar mixture of two lanthanide ions with close ionic radii. Right: Solid state ${ }^{86} \mathrm{Y}$ CPMAS NMR spectra of $\left(\left[\mathrm{Y}_{6} \mathrm{O}(\mathrm{OH})_{8}\left(\mathrm{NO}_{3}\right)_{6}\left(\mathrm{H}_{2} \mathrm{O}\right)_{12}\right] \cdot 2 \mathrm{NO}_{3} \cdot 2 \mathrm{H}_{2} \mathrm{O}\right.$ (bottom) and of $\left[\mathrm{Y}_{6-6 x} \mathrm{Lu}_{6 x} \mathrm{O}(\mathrm{OH})_{8}\left(\mathrm{NO}_{3}\right)_{6}\left(\mathrm{H}_{2} \mathrm{O}\right)_{12}\right] \cdot 2 \mathrm{NO}_{3} \cdot 2 \mathrm{H}_{2} \mathrm{O}$ with $x=1$ (Top). Redrawn from reference [169].

\section{From hexa-nuclear precursors to coordination polymers}

The use of octahedral hexa-nuclear complexes as molecular precursors for the design of infinite molecular networks is particularly appealing. Indeed, it allows the synthesis of coordination polymers in which the metallic nodes are hexa-nuclear complexes but no longer single lanthanide ions. This offers physical properties modulation and structural control.

However, as already underlined previously, these octahedral hexa-nuclear complexes are chemically easily damaged and have a reduced solubility in organic solvents. Their use as 
molecular precursors is therefore quite tricky and the choices of the ligand, the solvent and the operating conditions are crucial: (i) the use of dry alcohols or acetonitrile seems appropriate; (ii) the synthesis must be done in as dry atmosphere as possible; (iii) the ligands must be neither too acidic nor too basic. Because of these drastic conditions, several attempts have failed in the sense that hexa-nuclear complexes were destroyed during the synthetic process and the obtained coordination polymers present single ions as metallic nodes. However, it has been observed that the use of hexa-nuclear complexes as precursors leads to coordination polymers that would not be obtained from single lanthanide ions salts $[15,174,175]$. The model proposed by Calvez et al. assumes that the ligand approach and the destruction of the hexa-nuclear complex are simultaneous [171]. Therefore, only one part of the lanthanide ion is available for coordination by the ligand, the other part being shielded by the hexa-nuclear core which is not yet destroyed. This implies a coordination geometry that is different from that of an isolated lanthanide ion which is governed by steric hindrance effects (Fig. 25) [176, 177].
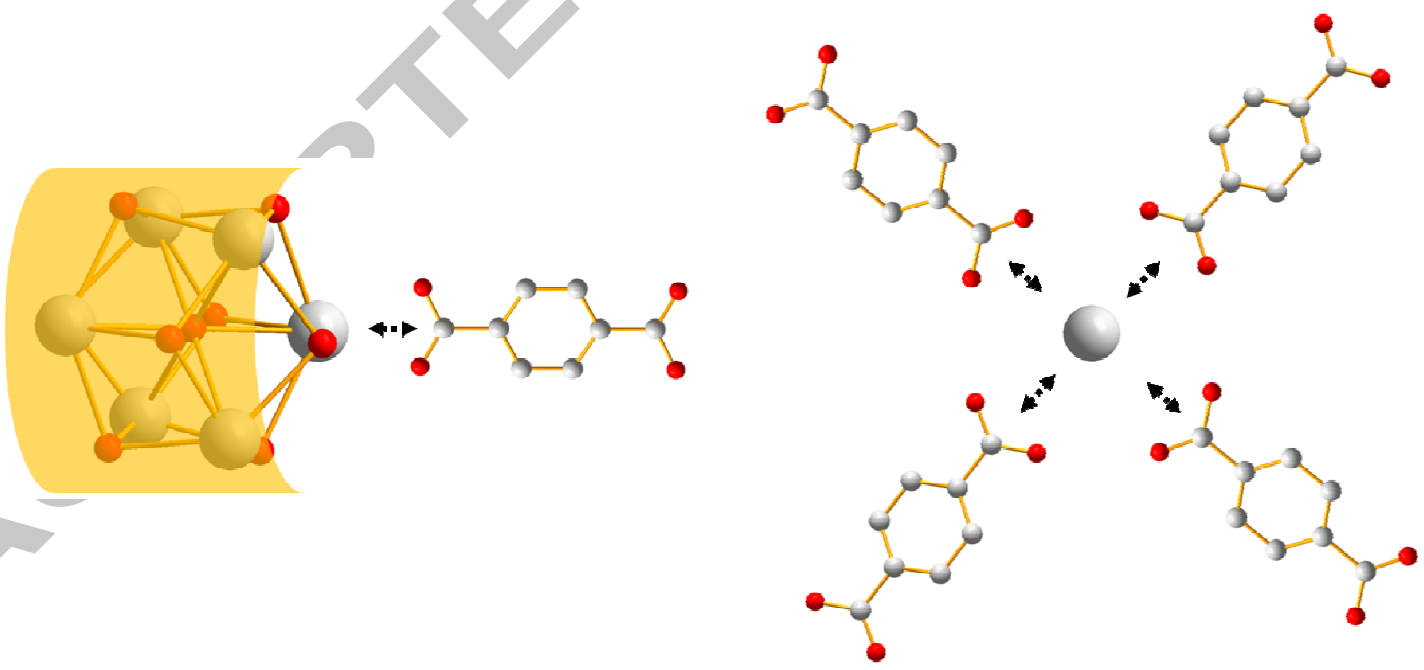

Fig. 25. Different potential approaches of a lanthanide ion that belongs to a hexa-nuclear complex (left) and of an isolated lanthanide ion (right) by a ligand. 
To date, only one series of coordination polymers exhibiting octahedral hexa-nuclear complexes as metallic centers and obtained from isolated hexa-nuclear precursor has been reported [25]. It has been obtained by solvothermal technique in dry acetonitrile at $130{ }^{\circ} \mathrm{C}$ from anhydrous octahedral hexa-nuclear complex and terephthalic acid $\left(\mathrm{H}_{2} \mathrm{bdc}\right)$. Homonuclear compounds that constitute the series have general chemical formula $\left[\mathrm{Ln}_{6} \mathrm{O}(\mathrm{OH})_{8}\left(\mathrm{NO}_{3}\right)_{2}(\mathrm{bdc})(\mathrm{Hbdc})_{2} \cdot 2 \mathrm{NO}_{3} \cdot \mathrm{H}_{2} \mathrm{bdc}\right]_{\infty}$ where $\mathrm{Ln}=\mathrm{Pr}-\mathrm{Lu}$ plus Y. Their crystal structure has been solved on the basis of the X-ray powder diffraction diagram of the yttrium derivative. It can be described as the juxtaposition of molecular chains in which hexa-nuclear complexes and fully deprotonated ligands alternate. Four out of the six bi-dentate nitrate ions that were present in the initial hexa-nuclear complexes are substituted by bi-dentate carboxylate groups from ligands. Fully deprotonated ligands link $\mathrm{Y}^{3+}$ ions in a bis-bidentate way to form the molecular chain. Half deprotonated ligands are bound to $\mathrm{Y}^{3+}$ ions in a bidentate fashion. The protonated part of the ligand points toward the inter-chains space (Fig. 26). Additionally, two nitrate ions and one fully protonated ligand per hexa-nuclear complex respectively insure the electro-neutrality of the framework and participates to its stability via hydrogen bonds and $\pi$-stacking interactions. 

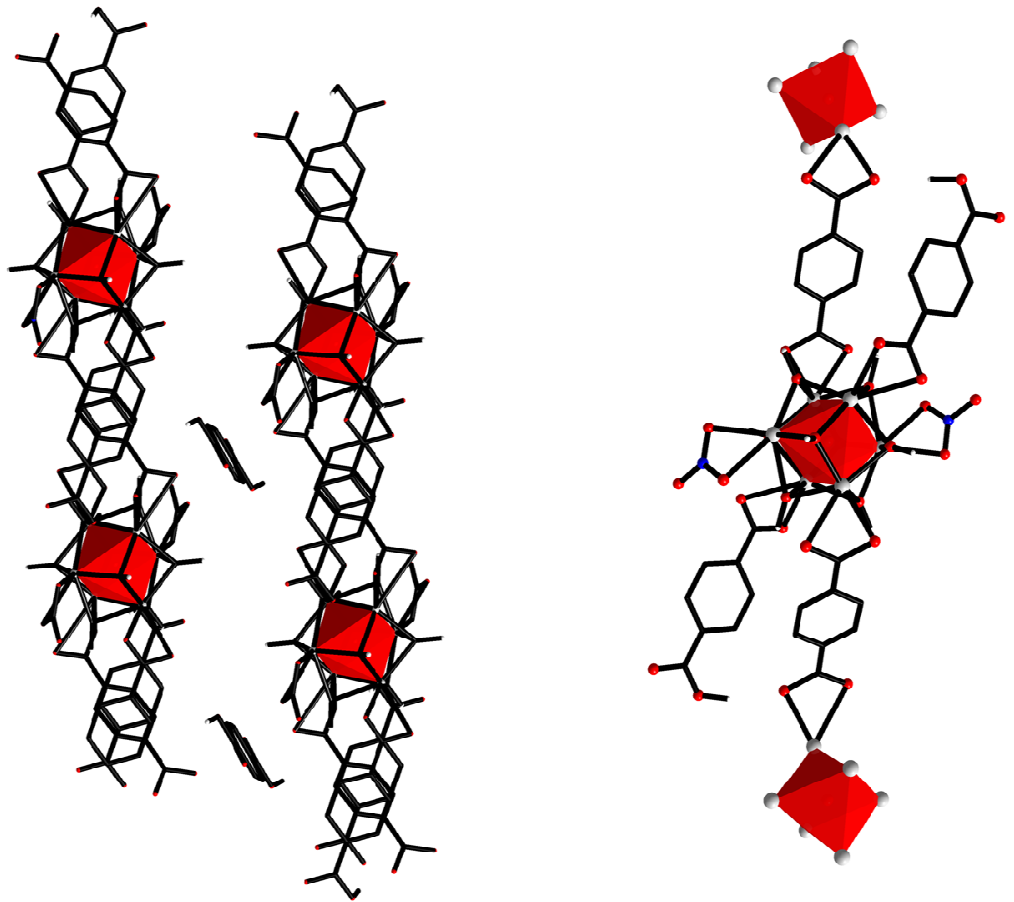

Fig. 26. Left: Projection view of two molecular chains of $\left[\mathrm{Y}_{6} \mathrm{O}(\mathrm{OH})_{8}\left(\mathrm{NO}_{3}\right)_{2}(\mathrm{bdc})(\mathrm{Hbdc})_{2} \cdot 2 \mathrm{NO}_{3} \cdot \mathrm{H}_{2} \mathrm{bdc}\right]_{\infty}$. Free nitrate ions have been omitted for clarity. Right: Perspective view of the neighborhood of an octahedral hexa-nuclear complex in $\left[\mathrm{Y}_{6} \mathrm{O}(\mathrm{OH})_{8}\left(\mathrm{NO}_{3}\right)_{2}(\mathrm{bdc})(\mathrm{Hbdc})_{2} \cdot 2 \mathrm{NO}_{3} \cdot \mathrm{H}_{2} \mathrm{bdc}\right]_{\infty}$. Redrawn from reference [25].

Luminescence of the $\mathrm{Tb}$ - and Eu-derivatives has been studied. This study demonstrates that terephthalate provides an efficient antenna effect. Moreover a strong intermetallic energy transfer has been evidenced.

Hetero-hexa-nuclear complexes can also be used as molecular precursors and lead to compounds that present the same crystal structure [169]. This is particularly interesting and validates the efficiency of the synthetic strategy. Indeed, it has been evidenced that there are two different intermetallic energy transfers that can be both independently tuned (Fig. 27). 


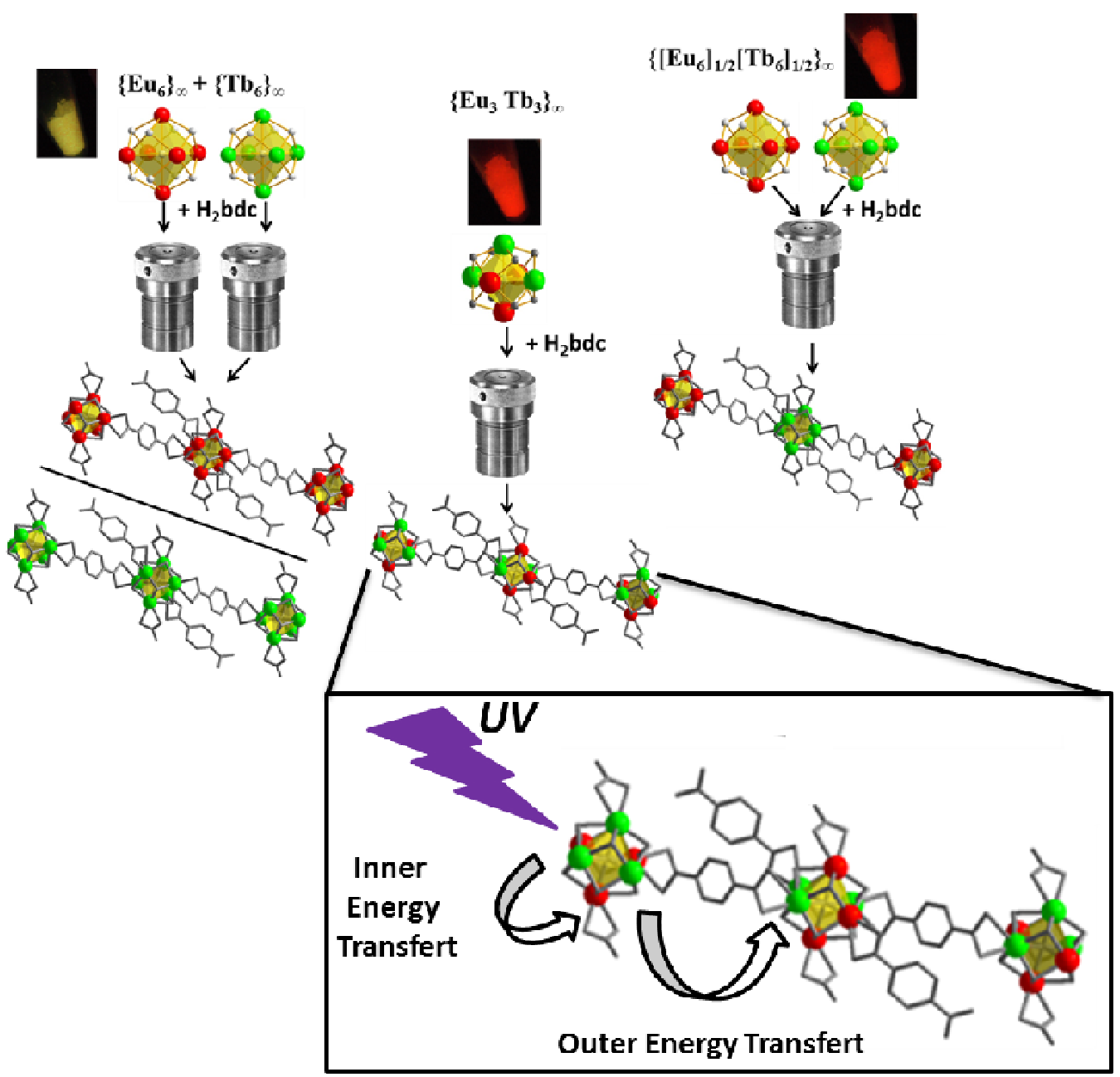

Fig. 27. Schematization of the preparation of three different microcrystalline powders. Left: Mixture of two microcrystalline powders. One based on Eu-based homo-hexa-nuclear complexes and the other one based on Tb-based homo-hexa-nuclear complexes. Middle: Monophasic microcrystalline powder based on hetero-hexa-nuclear complexes. Right: Monophasic microcrystalline powder based on a mixture of Eu- and Tb-based homo-hexanuclear complexes. In inset: Pictures of the three microcrystalline powders under UV irradiation. Bottom: Schematization of outer and inner intermetallic energy transfers. Redrawn from reference [169].

The first one, that acts inside a given hexa-nuclear complex, is similar to what is commonly encountered in conventional coordination polymers $[178,179]$ and is related to the short intermetallic distances $\left(2.9 \leq \mathrm{d}_{\text {Ln-Ln }}(\AA) \leq 4.2\right)$ inside the complex. As shown in Fig. 28, it can provides efficient brightness and color tunings of the emission. 

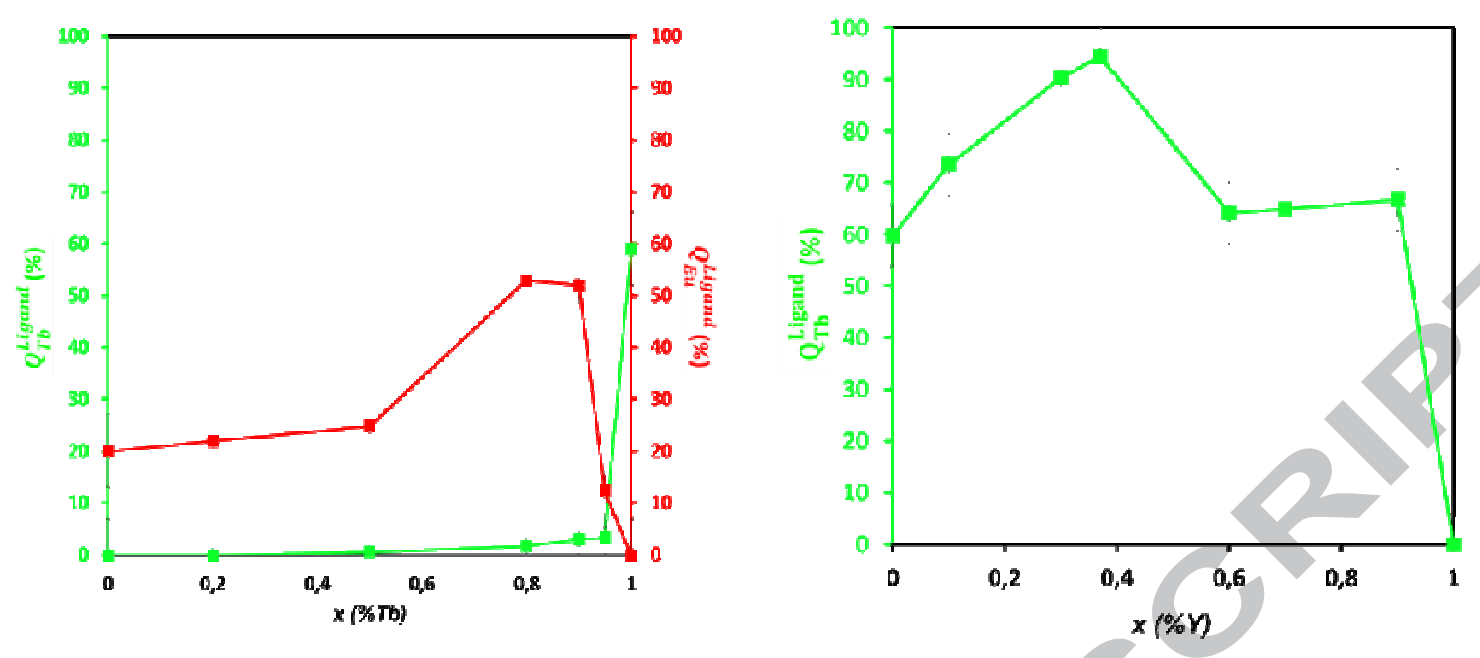

Fig 28. Left: Overall quantum yields $Q_{T b}^{\text {Ligand }}$ and $Q_{E u}^{\text {Ligand }}$ versus $x$ in $\left[\mathrm{Tb}_{6 x} \mathrm{Eu}_{6-}\right.$ ${ }_{6 x} \mathrm{O}(\mathrm{OH})_{8}\left(\mathrm{NO}_{3}\right)_{2}(\mathrm{bdc})(\mathrm{Hbdc})_{2} \cdot 2 \mathrm{NO}_{3} \cdot \mathrm{H}_{2}$ bdc $]_{\infty}$ with $0 \leq x \leq 1$. Right: Overall quantum yields $Q_{T b}^{\text {Ligand }}$ versus $x$ in $\left[\mathrm{Y}_{6 x} \mathrm{~Tb}_{6-6 x} \mathrm{O}(\mathrm{OH})_{8}\left(\mathrm{NO}_{3}\right)_{2}(\mathrm{bdc})(\mathrm{Hbdc})_{2} \cdot 2 \mathrm{NO}_{3} \cdot \mathrm{H}_{2} \mathrm{bdc}\right]_{\infty}$ with $0 \leq x \leq 1$.

The second one acts between lanthanide ions that belong to neighboring complexes. It has been evidenced $[169,180]$ that this second intermetallic energy transfer can be related to the well-known FRET phenomenon [181, 182]. To the best of our knowledge, it is the only series of compounds that presents simultaneously intermetallic energy transfers that are usually encountered in the solid state (inner interaction) and in the liquid state (outer interaction) (Fig. 27). This is of particular interest because it makes possible independent color and brightness tuning. Indeed it is possible for luminescence modulation purposes to play either with the composition of the hexa-nuclear precursors or with the mixture of different hexa-nuclear complexes. This constitutes an asset as far as taggants for fight against counterfeiting are targeted for example [183]. Indeed, a challenging problem in that field is the design of taggants that are as difficult as possible to counterfeit themselves. The use of hexa-nuclear complexes-based taggants would make more complex their structural characterization and their copy. Therefore it would improve the security level. 


\section{Conclusion}

In this short review we have tried to highlight that some lanthanide-based oxo/hydroxo poly-nuclear complexes can be used as molecular precursors for the design of new coordination compounds. These hexa-nuclear complexes can be conveniently isolated in the solid state as microcrystalline powders or in the liquid state either as nano-aggregates in polyols or dissolved in a dry organic solvent. They can be used as molecular precursors for the design of new hybrids materials that present original physical properties. We hope that we have succeeded in showing that chemistry of lanthanide-based hexa-nuclear entities is worth being further explored because it can lead to materials that exhibit unexpected and unprecedented physical behaviors. To date only luminescence in the visible has been explored but other photo-physical or magnetic properties could be interesting as well.

\begin{tabular}{ll} 
Abbreviations & \\
\hline Ac & acetate \\
bdc & benzene-1,4-dicarboxylate \\
bpdc & $4,4^{\prime}$-biphenyldicarboxylate \\
btz & benzotriazolate \\
bza & benzoate \\
Cp* & pentamethylcyclopentadienyl \\
DABCO & 1,4-diazabicyclo[2.2.2.]octane \\
DMF & dimethylformamide \\
DMSO & dimethylsulfoxide \\
Fum & butene-dicarboxylate \\
Mc & methacrylate \\
ndc & 2,6-naphtalenedicarboxylate \\
hpzc & 3-hydroxy-pyrazine-2-carboxylate \\
Piv & pivalate \\
THF & Tetrahydrofuran \\
TPPS & $5,10,15,20$-tetrakis(4-sulfonato-phenyl)porphyrin \\
\hline
\end{tabular}




\section{References}

[1] M. Eddaoudi, J. Kim, N. Rosi, D. Vodak, J. Wachter, M. O'Keeffe, O.M. Yaghi, Science, 295 (2002) 469-472.

[2] J.-C.G. Bünzli, Chem. Rev., 111 (2010) 2729-2755.

[3] S.V. Eliseeva, J.C.G. Bünzli, Chem. Soc. Rev., 39 (2010) 189-227.

[4] O. Guillou, C. Daiguebonne, G. Calvez, K. Bernot, Accounts Chem. Res., 49 (2016) 844-856.

[5] S.V. Eliseeva, J.C.G. Bünzli, New J. Chem., 35 (2011) 1165-1176.

[6] J.C.G. Bünzli, Coord. Chem. Rev., 293-294 (2015) 19-47.

[7] Y. Cui, B. Li, H. He, W. Zhou, B. Chen, G. Qian, Accounts Chem. Res., 49 (2016) 483-493.

[8] W.-X. Zhang, P.-Q. Liao, R.-B. Lin, Y.-S. Wei, M.H. Zeng, X.-M. Chen, Coord. Chem. Rev., 293-294 (2015) 263-278.

[9] S. Roy, A. Chakraborty, T.K. Maji, Coord. Chem. Rev., 273-274 (2014) 139-164.

[10] C. Benelli, D. Gatteschi, Introduction to Molecular Magnetism: From Transition Metals to Lanthanides, Wiley, 2015.

[11] A.J. Blake, N.R. Champness, P. Hubberstey, W.-S. Li, M.A. Withersby, M. SchrÃ $\llbracket$ der, Coord. Chem. Rev., 183 (1999) 117-138.

[12] F. Moreau, N. Audebrand, C. Poriel, V. Moizan-Basle, J. Ouvry, J. Mater. Chem., 21 (2011) 1871518722.

[13] L. Bogani, C. Sangregorio, R. Sessoli, D. Gatteschi, Angew. Chem. Int. Ed., 44 (2005) 5817-5821.

[14] D.G. Karraker, J. Chem. Educ., 47 (1970) 424-430.

[15] F. Le Natur, G. Calvez, S. Freslon, C. Daiguebonne, K. Bernot, O. Guillou, J. Mol. Struc., 1086 (2015) 34-42.

[16] Y. Luo, K. Bernot, G. Calvez, S. Freslon, C. Daiguebonne, O. Guillou, N. Kerbellec, T. Roisnel, Cryst. Eng. Comm., 15 (2013) 1882-1896.

[17] C. Serre, F. Millange, S. Surblé, G. Férey, Angew. Chem. Int. Ed., 43 (2004) 6286-6289.

[18] S. Surble, C. Serre, C. Mellot-Draznieks, F. Millange, G. Ferey, Chem. Comm., (2006) 284-286.

[19] S. Surble, F. Millange, C. Serre, G. Ferey, R.I. Walton, Chem. Comm., (2006) 1518-1520.

[20] X.-L. Wang, C. Qin, S.-X. Wu, K.-Z. Shao, Y.-Q. Lan, S. Wang, D.-X. Zhu, Z.-M. Su, E.-B. Wang, Angew. Chem. Int. Ed, 121 (2009) 5395-5399.

[21] V. Guillerm, S. Gross, C. Serre, T. Devic, M. Bauer, G. Ferey, Chem. Comm., 46 (2010) 767-769.

[22] S. Hausdorf, F. Baitalow, T. Böhle, D. Rafaja, F.O.R.L. Mertens, J. Am. Chem. Soc., 132 (2010) 10978-10981.

[23] Y.-Y. Liu, M. Grzywa, M. Weil, D. Volkmer, J. Solid State Chem., 183 (2010) 208-217.

[24] R. Nayuk, D. Zacher, R. Schweins, C. Wiktor, R.A. Fischer, G. van Tendeloo, K. Huber, J. Phys. Chem. C, 116 (2012) 6127-6135.

[25] G. Calvez, C. Daiguebonne, O. Guillou, Inorg. Chem., 50 (2011) 2851-2858.

[26] L.G. Westin, M. Kritikos, A. Caneschi, Chem. Comm., (2003) 1012-1013.

[27] G.R. Choppin, Rizkalla, Hydration and hydrolysis of lanthanides, in: J.a.L.E. Karl A. Gschneidner

(Ed.) Handbook on the Physics and Chemistry of Rare Earths, 1991, pp. 393-342.

[28] J. Kragten, L.G. Decnop-Weever, Talanta, 34 (1987) 861-864.

[29] J. Kragten, L.G. Decnop-Weever, Talanta, 30 (1983) 131-133.

[30] J. Kragten, L.G. Decnop-Weever, Talanta, 27 (1980) 1047-1050.

[31] U.K. Frolova, V.N. Kumok, V.V. Serebrennikov, Khim. i Khim. Tekhnol, 9 (1966) 176.

[32] T. Moeller, H.E. Kremers, Chem. Rev., 37 (1945) 97-159.

[33] M. Lundberg, A.J. Skarnulis, Acta Crystallogr. B, 32 (1976) 2944-2947.

[34] G.W. Beall, W.O. Milligan, D.R. Dillin, R.J. Williams, J.J. McCoy, Acta Crystallogr. B, 32 (1976) 2227-2229.

[35] R. Wang, H. Liu, M.D. Carducci, T. Jin, C. Zheng, Z. Zheng, Inorg. Chem., 40 (2001) 2743-2750.

[36] Y. Suzuki, T. Nagayama, M. Sekine, A. Mizuno, K. Yamaguchi, J. Less-Common Met., 126 (1986) 351-356. 
[37] R. Wang, H. Liu, M.D. Carducci, T. Jin, C. Zheng, Z. Zheng, Inorg. Chem., 40 (2001) 2743-2750.

[38] X. Xu, Eur. J. Lipid. Sci. Tech., 102 (2000) 287-303.

[39] N. Sahin, C.C. Akoh, A. Karaali, J. Agr. Food. Chem., 53 (2005) 5779-5783.

[40] Z.-C. Zhang, Acta Crystallogr. C, 64 (2008) m381-m383.

[41] Y.-Q. Sun, H.-X. Mei, H.-H. Zhang, Y.-P. Chen, R.-Q. Sun, J. Clust. Sci., 22 (2011) 279-288.

[42] X. Gu, D. Xue, Inorg. Chem., 46 (2007) 3212-3216.

[43] Z. Zheng, Chemtracts - Inorganic Chemistry, 16 (2003) 1-12.

[44] Z. Zheng, Chem. Comm., (2001) 2521-2529.

[45] Z. Zheng, Cluster Compounds of Rare-Earth Elements, in: K.A. Gschneidner, J.C.G. Bünzli, V.K. Pecharsky (Eds.) Hanbook on the Physics and Chemistry of Rare Earths, Elsevier, 2010, pp. 109-239.

[46] Z. Zheng, Chem. Comm., (2001) 2521-2529.

[47] R. Wang, M.D. Carducci, Z. Zheng, Inorg. Chem., 39 (2000) 1836-1837.

[48] R. Wang, T. Jin, Z. Zheng, Acta Chim. Sinica, 58 (2000) 1481-1492.

[49] Z. Zheng, R. Wang, Comment Inorg. Chem., 22 (2000) 1-30.

[50] R. Wang, Z. Zheng, T. Jin, R.J. Staples, Angew. Chem. Int. Ed., 38 (1999) 1813-1815.

[51] X.-J. Kong, L.-S. Long, L.-S. Zheng, R. Wang, Z. Zheng, Inorg. Chem., 48 (2009) 3268-3273.

[52] B.Q. Ma, D.S. Zhang, S. Gao, T.Z. Jin, C.H. Yan, New J. Chem., 24 (2000) 251-252.

[53] X.-J. Kong, Y. Wu, L.-S. Long, L.-S. Zheng, Z. Zheng, J. Am. Chem. Soc., 131 (2009) 6918-6919.

[54] A.T. Wagner, P.W. Roesky, Eur. J. Inorg. Chem., (2016) 782-791.

[55] L.G. Hubert-Pfalzgraf, N. Miele-Pajot, R. Papiernik, J. Vaissermann, J. Chem. Soc., Dalton Trans., (1999) 4127-4130.

[56] V. Baskar, P.W. Roesky, Z. Anorg. Allg. Chem., 631 (2005) 2782-2785.

[57] L.G. Hubert-Pfalzgraf, Coord. Chem. Rev., 178-180 (1998) 967-997.

[58] R.C. Mehrotra, A. Singh, U.M. Tripathi, Chem Rev, 91 (1991) 1287-1303.

[59] J. Gromada, A. Mortreux, T. Chenal, J.W. Ziller, F. Leising, J.F. Carpentier, Chem. Eur. J., 8 (2002) 3773-3788.

[60] W.J. Evans, M.A. Greci, J.W. Ziller, Inorg. Chem., 39 (2000) 3213-3220.

[61] M.R. Bürgstein, M.T. Gamer, P.W. Roesky, J. Am. Chem. Soc., 126 (2004) 5213-5218.

[62] M.R. Bürgstein, P.W. Roesky, Angew. Chem. Int. Ed., 39 (2000) 549-551.

[63] V. Guillerm, L. Weselinski, Y. Belmabkhout, A.J. Cairns, V. D'Elia, L. Wojtas, K. Adil, M. Eddaoudi, Nature Chemistry, 6 (2014) 673-680.

[64] D. Alezi, A.M.P. Peedikakkal, L. Weselinski, V. Guillerm, Y. Belmabkhout, A.J. Cairns, Z. Chen, L. Wojtas, M. Eddaoudi, J. Am. Chem. Soc., 137 (2015) 5421-5430.

[65] R. Luebke, Y. Belmabkhout, L. Weselinski, A.J. Cairns, M. Alkordi, G. Norton, L. Wotjas, K. Adil, M. Eddaoudi, Chem. Sci., 6 (2015) 4095-4102.

[66] D.-X. Xue, Y. Belmabkhout, O. Shekhah, H. Jiang, K. Adil, A.J. Cairns, M. Eddaoudi, J. Am. Chem. Soc., 137 (2015) 5034-5040.

[67] D.-X. Xue, A.J. Cairns, Y. Belmabkhout, L. Wojtas, Y. Liu, M. Alkordi, M. Eddaoudi, J. Am. Chem. Soc., 135 (2013) 7660-7667.

[68] G. Giester, Z. Zak, P. Unfried, J. Alloys Compd., 481 (2009) 116-128.

[69] G. Giester, P. Unfried, Z. Zak, J. Alloys Compd., 257 (1997) 175-181.

[70] P. Unfried, Thermochim. Acta, 303 (1997) 119-127.

[71] C.L. Lengauer, G. Giester, P. Unfried, Powder Diffr., 9 (1994) 115-118.

[72] Z. Zak, P. Unfried, G. Giester, J. Alloys Compd., 205 (1994) 235-242.

[73] P. Unfried, K. Rossmanith, Monatsh. Chem., 123 (1992) 1-8.

[74] P. Unfried, K. Rossmanith, H. Blaha, Monatsh. Chem., 122 (1991) 635-644.

[75] K. Rossmanith, P. Unfried, Monatsh. Chem., 120 (1989) 849-862.

[76] G. Calvez, O. Guillou, C. Daiguebonne, P.-E. Car, V. Guillerm, Y. Gérault, F.L. Dret, N. Mahé, Inorg. Chim. Acta, 361 (2008) 2349-2356.

[77] D. Pelloquin, D. Louër, M. Louër, J. Solid State Chem., 112 (1994) 182-188.

[78] Z. Zheng, R. Wang, Comments Inorg. Chem., 22 (2000) 1-30.

[79] D.S. Zhang, B.Q. Ma, T.Z. Jin, S. Gao, C.H. Yan, T.C.W. Mak, New J. Chem., 24 (2000) 61-62. 
[80] N. Mahé, O. Guillou, C. Daiguebonne, Y. Gérault, A. Caneschi, C. Sangregorio, J.Y. Chane-Ching, P.E. Car, T. Roisnel, Inorg. Chem., 44 (2005) 7743-7750.

[81] G. Giester, Z. Zak, P. Unfried, J. Alloys Compd., 481 (2009) 116-128.

[82] I.A. Charushnikova, C. Auwer, Crystallogr. Rep., 52 (2007) 226-229.

[83] D.N. Woodruff, R.E.P. Winpenny, R.A. Layfield, Chem Rev, 113 (2013) 5110-5148.

[84] J.-G. Kang, S.-K. Yoon, Y. Sohn, J.-G. Kim, Y.-D. Kim, I.-H. Suh, J. Chem. Soc., Dalton Trans., (1999) 1467-1474.

[85] A. Hosoi, Y. Yukawa, S. Igarashi, S.J. Teat, O. Roubeau, M. Evangelisti, E. Cremades, E. Ruiz, L.A. Barrios, G. Aromí, Chem. - Eur. J., 17 (2011) 8264-8268.

[86] H. He, X. Zhu, A. Hou, J. Guo, W.-K. Wong, W.-Y. Wong, K.-F. Li, K.-W. Cheah, Dalton Trans., (2004) 4064-4073.

[87] D.-Y. Wei, Y.-Q. Zheng, J.-L. Lin, Z. Naturforsch., Teil B 57 (2002) 625.

[88] J.P.R. de Villiers, J.C.A. Boeyens, Acta Crystallogr. B, 27 (1971) 692-702.

[89] H. He, D. Yuan, H. Ma, D. Sun, G. Zhang, H.-C. Zhou, Inorg. Chem., 49 (2010) 7605-7607.

[90] X. Yi, K. Bernot, F. Pointillart, G. Poneti, G. Calvez, C. Daiguebonne, O. Guillou, R. Sessoli, Chem. Eur. J., 18 (2012) 11379-11387.

[91] J.K. Tang, I.J. Hewitt, N.T. Madhu, G. Chastanet, W. Wernsdorfer, C.E. Anson, C. Benelli, R. Sessoli, A.K. Powell, Angew. Chem. Int. Ed., 45 (2006) 1729-1733.

[92] J. Luzon, K. Bernot, I.J. Hewitt, A.K. Powell, R. Sessoli, Phys. Rev. Lett., 100 (2008) 247205.

[93] M. Paluch, K. Slepokura, T. Lis, J. Lisowski, Inorg. Chem. Comm., 14 (2011) 92-95.

[94] J.-P. Costes, F. Dahan, F. Nicodeme, Inorg. Chem., 40 (2001) 5285-5287.

[95] M.J. Kobylka, K. Slepokura, M. Acebron Rodicio, M. Paluch, J. Lisowski, Inorg. Chem., 52 (2013) 12893-12903.

[96] S. Xue, X.-H. Chen, L. Zhao, Y.-N. Guo, J. Tang, Inorg. Chem., 51 (2012) 13264-13270.

[97] K.-L. Wong, Y.-M. Zhu, Y.-Y. Yang, G.-L. Law, H.-H. Fan, P.A. Tanner, W.-T. Wong, Inorg. Chem. Comm., 12 (2009) 52-54.

[98] W.J. Evans, M.S. Sollberger, Inorg. Chem., 27 (1988) 4417-4423.

[99] X. Ma, N. Xu, C. Gao, L. Li, B. Wang, W. Shi, P. Cheng, Dalton Trans., 44 (2015) 5276-5279.

[100] X. Yi, G. Calvez, C. Daiguebonne, O. Guillou, K. Bernot, Inorg. Chem., 54 (2015) 5213-5219.

[101] G. Abbas, Y. Lan, G.E. Kostakis, W. Wernsdorfer, C.E. Anson, A.K. Powell, Inorg. Chem., 49 (2010) 8067-8072.

[102] Y. Gao, G.-F. Xu, L. Zhao, J. Tang, Z. Liu, Inorg. Chem., 48 (2009) 11495-11497.

[103] D. Savard, P.-H. Lin, T.J. Burchell, I. Korobkov, W. Wernsdorfer, R. Clel rac, M. Murugesu, Inorg. Chem., 48 (2009) 11748-11754.

[104] P.H. Lin, I. Korobkov, W. Wernsdorfer, L. Ungur, L.F. Chibotaru, M. Murugesu, Inorg. Chem., 50 (2011) 1535-1539.

[105] X. Yi, K. Bernot, G. Calvez, C. Daiguebonne, O. Guillou, Eur. J. Inorg. Chem., 2013 (2013) 58795885.

[106] B.-Q. Ma, D.-S. Zhang, S. Gao, T.-Z. Jin, C.-H. Yan, G.-X. Xu, Angew. Chem. Int. Ed, 112 (2000) 3790-3792.

[107] H. Zhang, H. Yu, J. Ren, X. Qu, Biophys. J., 90 (2006) 3203-3207.

[108] V. Baskar, P.W. Roesky, Dalton Trans., (2006) 676-679.

[109] P.C. Andrews, W.J. Gee, P.C. Junk, J.G. MacLellan, Dalton Trans., 40 (2011) 12169-12179.

[110] E.H. Barash, P.S. Coan, E.B. Lobkovsky, W.E. Streib, K.G. Caulton, Inorg. Chem., 32 (1993) 497501.

[111] P.-H. Guo, J.-L. Liu, Z.-M. Zhang, L. Ungur, L.F. Chibotaru, J.-D. Leng, F.-S. Guo, M.-L. Tong, Inorg. Chem., 51 (2012) 1233-1235.

[112] P.-H. Lin, T.J. Burchell, L. Ungur, L.F. Chibotaru, W. Wernsdorfer, M. Murugesu, Angew. Chem. Int. Ed., 48 (2009) 9489-9492.

[113] S.K. Langley, N.F. Chilton, I.-A. Gass, B. Moubaraki, K.S. Murray, Dalton Trans., 40 (2011) 1265612659. 
[114] P.F. Yan, P.-H. Lin, F. Habib, T. Aharen, M. Murugesu, Z.P. Deng, G.M. Li, W.B. Su, Inorg. Chem., 50 (2011) 7059-7065.

[115] X.-Y. Chen, X. Yang, B.J. Holliday, Inorg. Chem., 49 (2010) 2583-2585.

[116] M.T. Gamer, Y. Lan, P.W. Roesky, A.K. Powell, R. Clel rac, Inorg. Chem., 47 (2008) 6581-6583.

[117] P.W. Roesky, G. Canseco-Melchor, A. Zulys, Chem. Comm., (2004) 738-739.

[118] P.C. Andrews, T. Beck, B.H. Fraser, P.C. Junk, M. Massi, B. Moubaraki, K.S. Murray, M. Silberstein, Polyhedron, 28 (2009) 2123-2130.

[119] P.C. Andrews, D.H. Brown, B.H. Fraser, N.T. Gorham, P.C. Junk, M. Massi, T.G. St Pierre, B.W. Skelton, R.C. Woodward, Dalton Trans., 39 (2010) 11227-11234.

[120] D.T. Thielemann, A.T. Wagner, Y. Lan, C.E. Anson, M.T. Gamer, A.K. Powell, P.W. Roesky, Dalton Trans., 42 (2013) 14794-14800.

[121] S. Datta, V. Baskar, H.L. Li, P.W. Roesky, Eur. J. Inorg. Chem., (2007) 4216-4220.

[122] D.T. Thielemann, I. Fernandez, P.W. Roesky, Dalton Trans., 39 (2010) 6661-6666.

[123] J.-Y. Ge, J. Ru, F. Gao, Y. Song, X.-H. Zhou, J.-L. Zuo, Dalton Trans., 44 (2015) 15481-15490.

[124] G.-M. Wang, J.H. Li, Z.-X. Li, P. Wang, Y.-X. Wang, J.H. Lin, Solid State Sci., 14 (2012) 445-450.

[125] T.S. Suskhikh, D.A. Bashirov, N.V. Kuratieva, A.I. Smolentsev, S.N. Konchenko, J Struct. Chem., 55 (2414) 1437-1441.

[126] R.J. Blagg, C.A. Muryn, E.J.L. Mc Innes, F. Tuna, R.E.P. Winpenny, Angew. Chem. Int. Ed., 50 (2011) 6530-6533.

[127] J.-B. Peng, X.-J. Kong, Y.P. Ren, L.-S. Long, R.B. Hiuang, L.S. Zheng, Inorg. Chem., 51 (2012) $2186-$ 2190.

[128] I.J. Hewitt, J. Tang, N.T. Madhu, C.E. Anson, Y. Lan, J. Luzon, M. Etienne, R. Sessoli, A.K. Powell, Angew. Chem. Int. Ed., 49 (2010) 6352-6356.

[129] D. Weng, X. Zheng, L. Jin, Eur. J. Inorg. Chem., (2006) 4184-4190.

[130] W.J. Evans, N.T. Allen, M.A. Greci, J.W. Ziller, Organometallics, 20 (2001) 2936-2937.

[131] J. Pickardt, S. Wiese, L. von Chrzanowski, M. Borowski, Z. Anorg. Allg. Chem., 626 (2000) 20962102.

[132] X. Fang, T.M. Anderson, C. Benelli, C.L. Hill, Chem. - Eur. J., 11 (2005) 712-718.

[133] S. Mishra, E. Jeanneau, S. Daniele, L.G. Hubert-Pfalzgraf, Cryst. Eng. Comm., 10 (2008) 814-816.

[134] O.T. Summerscales, D.R. Johnston, F.G.N. Cloke, P.B. Hitchcock, Organometallics, 27 (2008) 5612-5618.

[135] A.V. Mudring, T. Timofte, A. Babai, Inorg. Chem., 45 (2006) 5162-5166.

[136] A.-V. Mudring, A. Babai, Z. Anorg. Allg. Chem., 631 (2005) 261-263.

[137] N. Rukk, D. Al'bov, A. Skryabina, R. Osipov, L. Alikberova, Russ. J. Coord. Chem., 35 (2009) $12-$ 14.

[138] G. Calvez, C. Daiguebonne, O. Guillou, F. Le Dret, Eur. J. Inorg. Chem., (2009) 3172-3178.

[139] J. Liu, E.A. Meyers, S.G. Shore, Inorg. Chem., 37 (1998) 5410-5411.

[140] L.-F. Chen, J. Zhang, G.Q. Ren, L. Zhao-Ji, Y.-Y. Quin, P.-X. Yin, J.-K. Cheng, Y.-G. Yao, Cryst. Growth Des., 10 (2008) 1088-1092.

[141] F. Gandara, E. Gutierrez-Puebla, M. Iglesias, N. Snejko, M.A. Monge, Cryst. Growth Des., 10 (2010) 128-134.

[142] Y.Z. Tong, Q.L. Wang, G. Yang, G.M. Yang, S.P. Yan, D.Z. Liao, P. Cheng, Cryst. Eng. Comm., 12 (2010) 543-548.

[143] Y.-L. Hou, G. Xiong, P.F. Shi, R.R. Cheng, J.Z. Cui, B. Zhao, Chem. Comm., 49 (2013) 6066-6068.

[144] J. Demel, P. Kubat, F. Millange, J. Marrot, I. Cisarova, K. Lang, Inorg. Chem., 52 (2013) 27792786.

[145] F. Le Natur, G. Calvez, J.P. Guéguan, L. Le Polles, X. Trivelli, K. Bernot, C. Daiguebonne, C. Neaime, K. Costuas, F. Grasset, O. Guillou, Inorg. Chem., 54 (2015) 6043-6054.

[146] X.-J. Zheng, L.-P. Jin, S. Gao, Inorg. Chem., 43 (2004) 1600-1602.

[147] W.-H. Fang, L. Cheng, L. Huang, G.-Y. Yang, Inorg. Chem., 52 (2013) 6-8.

[148] J.W. Sharples, Y.-Z. Zheng, F. Tuna, E.J.L. Mc Innes, D. Collison, Chem. Comm., 47 (2011) 76507652. 
[149] A. Babai, A.-V. Mudring, Z. Anorg. Allg. Chem., 632 (2006) 1956-1958.

[150] S. Petit, F. Baril-Robert, G. Pilet, C. Reber, D. Luneau, Dalton Trans., (2009) 6809-6815.

[151] J.C.A. Boeyens, J.P.R. Villiers, J. Cryst. Mol. Struct., 2 (1972) 197-211.

[152] M. Volpe, G. Bombieri, D.A. Clemente, E. Foresti, M.D. Grillone, J. Alloys Compd., 374 (2004) 382-386.

[153] M. Addamo, G. Bombieri, E. Foresti, M.D. Grillone, M. Volpe, Inorg. Chem., 43 (2004) 16031605.

[154] M. Volpe, G. Bombieri, N. Marchini, J. Alloys Compd., 408-412 (2006) 1046-1051.

[155] K. Manseki, Y. Hasegawa, Y. Wada, H. Ichida, Y. Kanematsu, T. Kushida, J. Lumin., 122-123 (2007) 262-264.

[156] F.o. Baril-Robert, S. Petit, G. Pilet, G. Chastanet, C. Reber, D. Luneau, Inorg. Chem., 49 (2010) 10970-10976.

[157] R. Wang, H.D. Selby, H. Liu, M.D. Carducci, T. Jin, Z. Zheng, J.W. Anthis, R.J. Staples, Inorg. Chem., 41 (2002) 278-286.

[158] X.-L. Li, L.-F. He, X.-L. Feng, Y. Song, M. Hu, L.-F. Han, X.-J. Zheng, Z.-H. Zhang, S.-M. Fang, Cryst. Eng. Comm., 13 (2011) 3643-3645.

[159] M.B. Zhang, J. Zhang, S.T. Zheng, G.Y. Yang, Angew. Chem. Int. Ed., 44 (2005) 1385-1388.

[160] R. Wang, D. Song, S. Wang, Chem. Comm., (2002) 368-369.

[161] D.T. Thielemann, A.T. Wagner, E. Rösch, D.K. Kölmel, J.G. Heck, B. Rudat, M. Neumaier, C. Feldmann, U. Schepers, S. Bräse, P.W. Roesky, J. Am. Chem. Soc., 135 (2013) 7454-7457.

[162] L. Huang, L. Han, W. Feng, L. Zheng, Z. Zhang, Y. Xu, Q. Chen, D. Zhu, S. Niu, Cryst. Growth Des., 10 (2010) 2548-2552.

[163] F.-S. Guo, Y.C. Chen, L.-L. Mao, W.-Q. Lin, J.-D. Leng, R. Tarasenko, M. Orendac, J. Prokleska, V. Sechovsky, M.-L. Tong, Chem. - Eur. J., 19 (2013) 14876-14885.

[164] J.-B. Peng, X.-J. Kong, Q.-C. Zhang, M. Orendac, J. Prokleska, Y.P. Ren, L.-S. Long, Z. Zheng, L.-S. Zheng, J. Am. Chem. Soc., 136 (2014) 17938-17941.

[165] E.M. Flanigen, P.A. Jacobs, J.C. Jansen, H.v. Bekkum, in Introduction to Zeolite Science and Practice, Elsiever, New York, (1991).

[166] Y.-C. Chen, J.-L. Liu, M.-L. Tong, 4f-Clusters for Cryogenic Magnetic Cooling, in, Springer Berlin Heidelberg, Berlin, Heidelberg, 2015, pp. 1-19.

[167] A.V. Mudring, T. Timofte, A. Babai, Inorg. Chem., 45 (2006) 5162-5166.

[168] F. Le Natur, G. Calvez, O. Guillou, C. Daiguebonne, K. Bernot, Acta Crystallogr. E, E70 (2014) 577-579.

[169] F. Le Natur, G. Calvez, C. Daiguebonne, O. Guillou, K. Bernot, J. Ledoux, L. Le Polles, C. Roiland, Inorg. Chem., 52 (2013) 6720-6730.

[170] D. Louër, M. Louër, Eur. J. Sol. State Inor., 26 (1989) 241-253.

[171] G. Calvez, C. Daiguebonne, O. Guillou, T. Pott, P. Méléard, F. Le Dret, C. R. Chimie, 13 (2010) 715-730.

[172] C. Hennig, A. Ikeda-Ohno, W. Kraus, S. Weiss, P. Pattison, H. Emerich, P.M. Abdala, A.C. Scheinost, Inorg. Chem., 52 (2013) 11734-11743.

[173] A.L. Estes, M.R. Antonio, L. Soderholm, J. Phys. Chem. C, 120 (2016) 5810-5818.

[174] O. Guillou, C. Daiguebonne, G. Calvez, F. Le Dret, P.E. Car, J. Alloys Compd., 451 (2008) 329-333.

[175] G. Calvez, K. Bernot, O. Guillou, C. Daiguebonne, A. Caneschi, N. Mahé, Inorg. Chim. Acta, 361 (2008) 3997-4003.

[176] C. Daiguebonne, O. Guillou, Y. Gérault, A. Lecerf, K. Boubekeur, Inorg. Chim. Acta, 284 (1999) 139-145.

[177] X.-Z. Feng, A.-L. Guo, Xu, Y.-T., X.-F. Li, P.-N. Sun, Polyhedron, 6 (1987) 1041-1048.

[178] S. Freslon, Y. Luo, C. Daiguebonne, G. Calvez, K. Bernot, O. Guillou, Inorg. Chem., 55 (2016) 794802.

[179] V. Haquin, M. Etienne, C. Daiguebonne, S. Freslon, G. Calvez, K. Bernot, L. Le Polles, S.E. Ashbrook, M.R. Mitchell, J.C.G. Bünzli, O. Guillou, Eur. J. Inorg. Chem., (2013) 3464-3476.

[180] F. Le Natur, in, PhD Thesis INSA Rennes, 2014, pp. 246. 
[181] P.R. Selvin , T.M. Rana, J.E. Hearst, J. Am. Chem. Soc., 116 (1994) 6029-6030. [182] J.-Q. Gu, J. Shen, L.-D. Sun, C.-H. Yan, J. Phys. Chem. C, 112 (2008) 6589-6593.

[183] G. Calvez, O. Guillou, F. Le Natur, (2012) French patent n FR2995316-A1. 


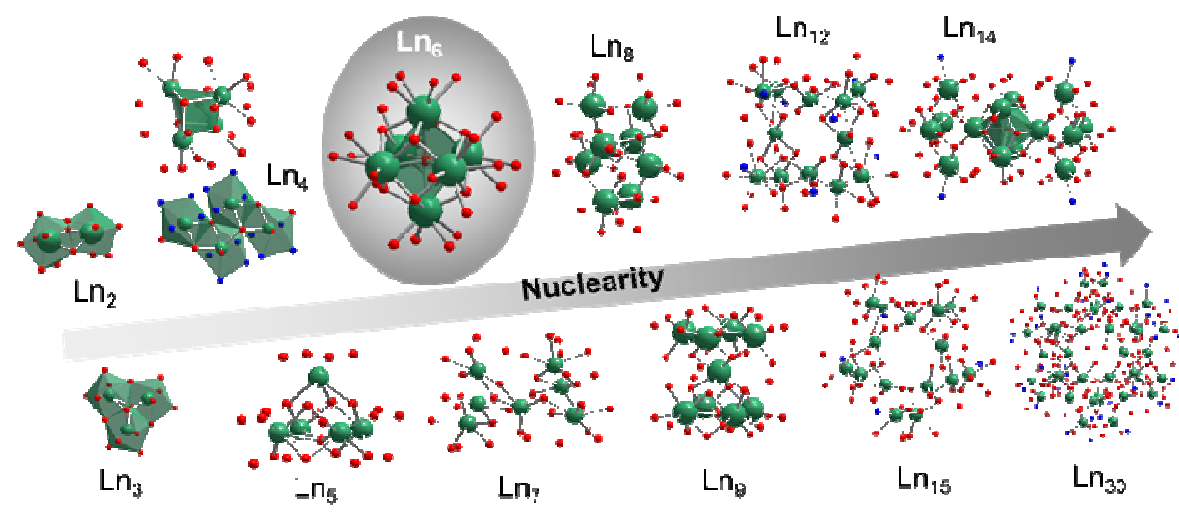


Synthesis of stable lanthanide-based oxo/hydroxo octahedral hexa-nuclear complexes.

Use of lanthanide-based octahedral hexa-nuclear complexes as molecular precursors.

Synthesis of hetero-hexa-nuclear lanthanide based complexes.

Photo-physical properties of lanthanide hexa-nuclear complexes-based coordination polymers. 